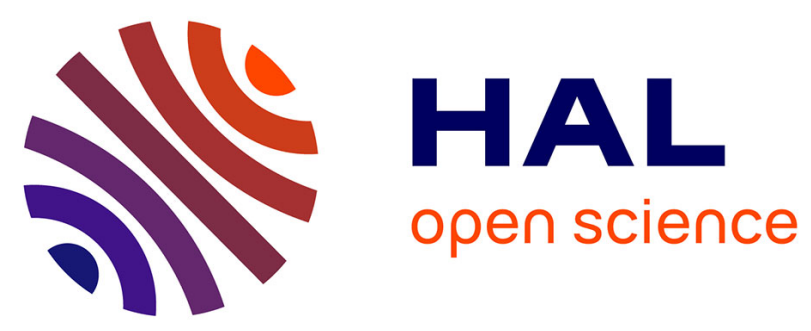

\title{
Saline pulse test monitoring with the self-potential method to nonintrusively determine the velocity of the pore water in leaking areas of earth dams and embankments
}

S. J. Ikard, A. Revil, Abderrahim Jardani, W. F. Woodruff, M. Parekh, M.

Mooney

\section{To cite this version:}

S. J. Ikard, A. Revil, Abderrahim Jardani, W. F. Woodruff, M. Parekh, et al.. Saline pulse test monitoring with the self-potential method to nonintrusively determine the velocity of the pore water in leaking areas of earth dams and embankments. Water Resources Research, 2012, 48, pp.W04201. 10.1029/2010WR010247 . hal-00734735

\section{HAL Id: hal-00734735 \\ https://hal.science/hal-00734735}

Submitted on 24 Sep 2021

HAL is a multi-disciplinary open access archive for the deposit and dissemination of scientific research documents, whether they are published or not. The documents may come from teaching and research institutions in France or abroad, or from public or private research centers.
L'archive ouverte pluridisciplinaire HAL, est destinée au dépôt et à la diffusion de documents scientifiques de niveau recherche, publiés ou non, émanant des établissements d'enseignement et de recherche français ou étrangers, des laboratoires publics ou privés.

$$
\text { Copyright }
$$




\title{
Saline pulse test monitoring with the self-potential method to nonintrusively determine the velocity of the pore water in leaking areas of earth dams and embankments
}

\author{
S. J. Ikard, ${ }^{1}$ A. Revil, ${ }^{1,2}$ A. Jardani, ${ }^{3}$ W. F. Woodruff, ${ }^{1}$ M. Parekh, ${ }^{4}$ and M. Mooney ${ }^{4}$ \\ Received 15 November 2010; revised 17 March 2012; accepted 20 March 2012; published 28 April 2012.
}

[1] A method is proposed to localize preferential fluid flow pathways in porous media on the basis of time-lapse self-potential measurements associated with salt tracer injection upstream. This method is first tested using laboratory data. A network of nonpolarizing electrodes located is connected to a highly sensitive voltmeter used to record the resulting electrical field fluctuations occurring over time at the surface of the tank. The transport of the conductive salt plume through the permeable porous materials changes the localized streaming potential coupling coefficient associated with the advective drag of the excess charge of the pore water and is also responsible for a diffusion current associated with the salinity gradient. Monitoring of the electrical potential distribution at the ground surface can be used to localize the pulse of saline water over time and to determine its velocity. This method applies in real time and can be used to track highly localized flow pathways characterized by high permeability. Our sandbox experiment demonstrates the applicability of this new method under well-controlled conditions with a coarse-sand channel embedded between fine-sand banks. A finite element model allows us to reproduce the time-lapse electrical potential distribution over the channel, but some discrepancies were observed on the banks. Finally, we performed a numerical simulation for a synthetic case study inspired by a recently published field case study. A Markov chain Monte Carlo sampler is used to determine the permeability and the porosity of the preferential fluid flow pathway of this synthetic case study.

Citation: Ikard, S. J., A. Revil, A. Jardani, W. F. Woodruff, M. Parekh, and M. Mooney (2012), Saline pulse test monitoring with the self-potential method to nonintrusively determine the velocity of the pore water in leaking areas of earth dams and embankments, Water Resour. Res., 48, W04201, doi:10.1029/2010WR010247.

\section{Introduction}

[2] The self-potential method is a nonintrusive geophysical method corresponding to the passive measurements of the electrical potential distribution at a given set of stations using nonpolarizing electrodes [De Witte, 1948; Ogilvy et al., 1969]. The differences of voltages between these stations and a reference electrode are measured with a voltmeter characterized by a sensitivity larger than $0.1 \mathrm{mV}$ and a high input impedance ( $>10 \mathrm{M} \Omega$ ). Self-potential mapping has been applied for decades to qualitatively detect preferential fluid flow pathways in embankments and earth dams [Ogilvy et al., 1969; Gex, 1980; Sill and Killpack, 1982; Merkler et al., 1989; Wilt and Corwin, 1989; Wilt and

\footnotetext{
${ }^{1}$ Department of Geophysics, Colorado School of Mines, Golden, Colorado, USA.

${ }^{2}$ ISTerre, UMR CNRS 5275, Université de Savoie, Le Bourget du Lac, France.

${ }^{3}$ UMR 6143 CNRS, Université de Rouen, Mont-Saint-Aignan, France.

${ }^{4}$ Division of Engineering, Colorado School of Mines, Golden, Colorado, USA.
}

Copyright 2012 by the American Geophysical Union 0043-1397/12/2010WR010247
Butler, 1990; Al-Saigh et al., 1994; Sheffer and Howie, 2001, 2003]. Typical steady state self-potential anomalies associated with earth dams amount to several tens of $\mathrm{mV}$ (32 $\mathrm{mV}$ in the earth dam investigated by Panthulu et al. [2001], $80 \mathrm{mV}$ in the embankment dam analyzed by Bolève et al. [2009], and $80 \mathrm{mV}$ in the work of Rozycki [2009]) and sometimes hundreds of millivolts $(300 \mathrm{mV}$ in the earth dam investigated by Rozycki et al. [2006], $400 \mathrm{mV}$ for the case study reported by Asfahani et al. [2010], over $200 \mathrm{mV}$ at Dana Lake [see Moore et al., 2011], and $170 \mathrm{mV}$ at Hidden Dam [see Minsley et al., 2011]).

[3] In the last decade or so, the self-potential method has emerged as a powerful quantitative tool in determining flow properties in such settings [Titov et al., 2000; Rozycki et al., 2006; Sheffer and Oldenburg, 2007; Rozycki, 2009; Bolève et al., 2009] and for groundwater flow testing [e.g., Jardani and Revil, 2009; Malama et al., 2009a, $2009 \mathrm{~b}$ ]. The underlying theory of self-potential signals in steady state conditions is indeed fairly well known (see Revil et al. [2011] for a recent unified model) and can be quite easily coupled to the flow of the groundwater to predict the self-potential response associated with a given geometry, material and pore fluid properties, boundary conditions, and forcing terms. 
[4] However, despite the number of published works in this domain, we feel that the potential of this method has not yet been unleashed. So far, only individual selfpotential maps have been used to identify preferential fluid flow pathways. This approach presents some limitations. If the ground is characterized by a very heterogeneous resistivity distribution, the self-potential map can be characterized by spatial fluctuations with different wavelengths (see Sheffer [2007] and Bolève [2009] for some field examples). In this case, the preferential flow pathways may be difficult to identify even when applying specific filters to the raw data (in the Fourier or wavelet-based methods, for instance). Some works have been done in identifying flow paths by changing the flow conditions and by monitoring the change of the self-potential signals [Sheffer, 2002], and our work follows this idea.

[5] Following Revil and coworkers [Bolève, 2009; Revil and Jardani, 2010; Martínez-Pagán et al., 2010; Bolève et al., 2011], we propose a new method based on the injection of salt upstream of a heterogeneous porous material and the time-lapse monitoring of the self-potential response at the ground surface to detect and image preferential fluid flow pathways between an upstream reservoir and a downstream reservoir. We call this test SMART (self-potential monitored salt tracer test). In this paper, we first develop a complete theory for SMART to characterize the change in the self-potential field associated with the advectiondispersion of saline tracer in a porous material (section 2). Next, we developed a sandbox experiment to test the theory (section 3). Section 4 presents a numerical model of the sandbox experiment. In section 5.1, we discuss the application of this method to the field experiment reported by Bolève [2009]. This experiment has not been modeled to date and we propose a numerical test of our approach to a 2-D synthetic model inspired by this field case study. In section 5.3., we also discuss the advantages of this approach over the more classical time-lapse direct current (DC) resistivity tomography approach.

\section{Background Theory}

[6] We first recall the transport equations for the migration of a salt tracer in a water-saturated porous material, neglecting the effect of salt concentration upon dynamic viscosity and mass density of the pore water. Indeed, we are dealing with relatively weak salt salinities in contrast to Revil and Jardani [2010] and Martínez-Pagán et al. [2010] who used a brine at saturation with respect to the salt. Therefore we neglect the buoyancy force below. The field equations for the fluid pressure and the concentration are obtained by combining two constitutive equations, Darcy's law for the Darcy velocity $\mathbf{u}$ (in $\mathrm{m} \mathrm{s}^{-1}$ ), and a generalized Fick's law for the mass flux of the salt $\mathbf{j}_{d}$ (in $\mathrm{kg} \mathrm{m}^{-2} \mathrm{~s}^{-1}$ ) together with two continuity equations, one for the mass of the pore water and one for the mass of the salt. The constitutive equations are given by

$$
\begin{gathered}
\mathbf{u}=\phi \mathbf{v}=-\frac{1}{\eta_{f}} \mathbf{k} \cdot\left(\nabla p+\rho_{f} g \nabla z\right), \\
\mathbf{j}_{d}=-\rho_{f} \phi \mathbf{D} \cdot \nabla C_{m}+\rho_{f} \phi \mathbf{v} C_{m} .
\end{gathered}
$$

The continuity equations are given by

$$
\begin{gathered}
\nabla \cdot\left(\rho_{f} \mathbf{u}\right)=-\frac{\partial\left(\rho_{f} \phi\right)}{\partial t}+\rho_{f} Q_{s} \\
\nabla \cdot \mathbf{j}_{d}=-\frac{\partial\left(\rho_{f} \phi C_{f}\right)}{\partial t}+\rho_{f} Q_{s} C_{f}^{0} .
\end{gathered}
$$

In these equations, $\mathbf{v}$ is the mean velocity of the pore water in the pore space $\left(\mathrm{m} \mathrm{s}^{-1}\right), \mathbf{k}$ is the permeability tensor $\left(\right.$ in $\left.\mathrm{m}^{2}\right), \mathbf{D}\left(\right.$ in $\left.^{2} \mathrm{~s}^{-1}\right)$ is the effective hydrodynamic dispersion tensor, $\phi$ porosity, $p$ is the pore fluid pressure $(\mathrm{Pa}), \eta_{f}$ is the dynamic viscosity of the pore fluid (in Pa s), $\rho_{f}$ is the solute bulk density (in $\mathrm{kg} \mathrm{m}^{-3}$ ), $g$ is the acceleration of gravity (in $\mathrm{m} \mathrm{s}^{-2}$ ), $Q_{S}$ is a source term for the injection/ abstraction of water (in $\left.\mathrm{s}^{-1}\right), C_{f}$ is the solute mass fraction (dimensionless), and $C_{f}^{0}$ is the solute mass fraction in the source term.

[7] To represent the dispersivity tensor, we use the Fickian dispersion model for its simplicity, but other available dispersion models could be used as well. With this assumption, the effective hydrodynamic dispersion tensor entering equation (2) is given by

$$
\mathbf{D}=\left[\frac{D_{f}}{F \phi}+\alpha_{T} v\right] \mathbf{I}+\frac{\alpha_{L}-\alpha_{T}}{v} \mathbf{v} \otimes \mathbf{v},
$$

where $D_{f}$ is the molecular diffusion coefficient of the salt (in $\mathrm{m}^{2} \mathrm{~s}^{-1}$ ) (for a $\mathrm{NaCl}$ solution, $D_{f}$ typically is between $1.60 \times 10^{-9} \mathrm{~m}^{2} \mathrm{~s}^{-1}$ at infinite dilution and $1.44 \times 10^{-9}$ $\mathrm{m}^{2} \mathrm{~s}^{-1}$ at high salinities at $\left.25^{\circ} \mathrm{C}\right), v=|\mathbf{v}|, \mathbf{I}$ is the unit tensor, $\mathbf{a} \otimes \mathbf{b}$ represents the tensor product between vectors a and $\mathbf{b}, \alpha_{L}$ and $\alpha_{T}$ are the longitudinal and transverse dispersivities (in $\mathrm{m}$ ), respectively, and the product of the formation factor $F$ by the porosity $\phi$ represents the tortuosity of the pore space [Pfannkuch, 1972; Johnson and Sen, 1988].

[8] The generation of an electrical field measured by the self-potential method is related to the existence of a source current density in the conductive porous medium. The total electrical current density $\mathbf{j}$ is given by an extended Ohm's law [Prigogine, 1947; Overbeek, 1952; Helfferich, 1995]:

$$
\mathbf{j}=\sigma \mathbf{E}+\mathbf{j}_{S}
$$

where $\mathbf{E}$ is the electrical field (in $\mathrm{V} \mathrm{m}^{-1}$ ) $\mathbf{E}=-\nabla \psi$ (to honor $\nabla \times \mathbf{E}=0$ in the quasi-static limit of the Maxwell equations), $\psi$ is the electrical potential (in V), $\sigma$ is the electrical conductivity of the porous material (in $\mathrm{S} \mathrm{m}^{-1}$ ), and $\mathbf{j}_{S}$ is the source current density (in $\mathrm{A} \mathrm{m}^{-2}$ ). In the lowfrequency limit of the Maxwell equation, and without external injection or retrieval of electrical charges, the continuity equation for the charge is given as

$$
\nabla \cdot \mathbf{j}=0 .
$$

[9] In the case of a salt plume moving in a porous material, there are two contributions of the total source current density generating self-potential signals. The first contribution is associated with the flow of the pore water itself. It is called the streaming current density [Helfferich, 1995]. The 
second contribution is related to the gradient of the salinity and is called the diffusion current density [Newman, 1991; Helfferich, 1995] and was neglected by Bolève et al. [2009]. We will show below that this contribution is actually far from being negligible and needs to be accounted for. The total source current density is therefore given by [Revil and Linde, 2006; Revil and Jardani, 2010; Martínez-Pagán et al., 2010]

$$
\mathbf{j}_{S}=\bar{Q}_{V} \mathbf{u}-k_{b} T \sum_{i=1}^{N} \frac{t_{i} \sigma}{q_{i}} \nabla \ln \{i\} .
$$

As a side note, Revil and Linde [2006] derived this equation using a volumetric averaging approach of the local Nernst-Planck equation. The first term of the right-hand side of equation (8) corresponds to the streaming current density and the second term corresponds to the diffusion current density. The variable $T$ represents the absolute temperature (in $\mathrm{K}$ ), $k_{b}$ denotes the Boltzmann constant $\left(1.381 \times 10^{-23} \mathrm{~J} \mathrm{~K}^{-1}\right), \bar{Q}_{V}$ (in $\mathrm{C} \mathrm{m}^{-3}$ ) is the effective charge of the electrical diffuse layer per unit pore volume that can be dragged by the flow of the pore water, $q_{i}$ (in C) is the charge of species $i$ dissolved in water, $t_{\mathrm{i}}$ (dimensionless) is the microscopic Hittorf number of the ionic species $i$ in the pore water. This microscopic Hittorf number represents the fraction of electrical current carried by species $i$ in the aqueous phase. The term $\{i\}$ represents the activity (concentration times the activity coefficient, unitless) of the ionic species $i$. In the case reported below, the complete dissociation of $\mathrm{NaCl}(\mathrm{s})$ provides two ionic species $\mathrm{Na}^{+}$and $\mathrm{Cl}^{-}$to the pore water.

[10] The charge per unit pore volume $\bar{Q}_{V}$ is salinity dependent and to be consistent with the Helmholtz-Smoluchowski equation at thermodynamic equilibrium between the pore water and the mineral surface, this salinity dependence has to be the same as the salinity dependence of the zeta potential, the inner potential of the electrical double layer. Revil et al. [1999, Figure 4] showed that the zeta potential (hence the charge density $\bar{Q}_{V}$ ) changes by one order of magnitude over 6 orders of magnitude in salinity change for silica sands. Therefore the salinity dependence of $\bar{Q}_{V}$ can be neglected at first approximation. There is also another reason to keep this parameter constant in the following analysis: the change in the zeta potential or in $\bar{Q}_{V}$ with the salinity is controlled by the sorption of cations in the Stern layer (the inner part of the electrical double layer). Usually, the salt tracer experiments reported below takes only few minutes while the kinetics of sorption of sodium on silica takes few tens of minutes to several hours [Revil et al., 1999].

[11] Revil [1999] showed that, in a diffusion problem, one might replace the gradient of the logarithm of the activity of the salt by the gradient of the logarithm of the electrical conductivity of the salt. Using this approach, we can rewrite the total source current as (see Appendix A)

$$
\mathbf{j}_{S}=\bar{Q}_{V} \mathbf{u}-\frac{k_{b} T}{e} \sigma\left(2 t_{(+)}-1\right) \nabla \ln \sigma_{f}
$$

where $e$ is the elementary charge of the electron, $t_{(+)}$is the microscopic Hittorf number of the cation (see values by Revil [1999], $t_{(+)}=0.38$ for a sodium chloride solution), and $\sigma_{f}$ is the conductivity of the pore water (in $\mathrm{S} \mathrm{m}^{-1}$ ), which is proportional to the salinity at a given temperature. equation (9) has been successfully used in a number of recent studies [Revil and Jardani, 2010; Martínez-Pagán et al., 2010; Woodruff et al., 2010]. Its derivation is summarized in Appendix A.

[12] In a clay-free sand at low Dukhin numbers [e.g., Crespy et al., 2008; Bolève et al., 2007] (see also Appendix A), the conductivity of the sand $\sigma$ is linearly related to the conductivity of the pore water $\sigma_{f}$ by [Archie, 1942; Clavier et al., 1977]

$$
\sigma=\frac{\sigma_{f}}{F}
$$

The formation factor is related to the connected porosity $\phi$ by Archie's law: $F=\phi^{-m}$ [Archie, 1942], where $m$ is called the cementation exponent (typically, 1.3 for wellsorted clean sand as used in the following experiment [e.g., Hallenburg, 1998, p. 127; Revil and Florsch, 2010; Revil, 1999]. From equations (9) and (10), the total source current density can be rewritten as (see Appendix A)

$$
\mathbf{j}_{S}=\bar{Q}_{V} \mathbf{u}-\frac{k_{b} T}{F e}\left(2 t_{(+)}-1\right) \nabla \sigma_{f} .
$$

[13] Combining equations (6) and (7), the self-potential field $\psi$ is the solution of the following Poisson equation:

$$
\nabla \cdot(\sigma \nabla \psi)=\nabla \cdot \mathbf{j}_{S}
$$

where the source term (the right-hand side of equation (12)) can be directly related to the Darcy velocity field u and to the gradient of the conductivity of the pore water through equation (11). Both the Darcy velocity and the salinity are obtained by solving equations (1)-(4) (the socalled primary flow problem) with appropriate boundary conditions.

[14] In the case of the laboratory experiment presented below, the boundary conditions include an insulating boundary conditions for the electrical potential at the top surface of a tank and on the side boundaries and impervious boundary conditions except between the reservoirs and the sandbox containing the sand. An important point is that the self-potential field is never measured in an absolute sense. The measured electrical potentials at a given set of nonpolarizing electrodes are measured with respect to a reference electrode for which the electrical potential is considered to be, by definition, equal to zero. The position of the reference electrode needs to be accounted for when comparing numerical modeling with the experimental results.

\section{Laboratory Experiment}

[15] The goal of this experiment is to determine if, by measuring the fluctuations of the electrical field at the top surface of a sandbox, we can visualize nonintrusively a preferential flow pathway that is illuminated by the advective transport of salt dissolved in water.

\subsection{Material and Methods}

[16] The tank consists of two reservoirs, upstream reservoir 1 for injection and downstream reservoir 2 for pumping, 
and the sand medium in between (Figure 1). The two reservoirs are separated by a distance of $0.99 \mathrm{~m}$, as shown in Figure 1. The sandbox comprises a central channel of coarse sand (sand A), bounded by two flanking banks of fine sand (sand B; Figure 1d). The sands were placed dry in layers of $20 \mathrm{~mm}$, and tamped. The material properties of the two sands are described in Table 1, and we assume the porosities are consistent between our experiment and the experiments made by T. Sakaki (Physical, hydraulic, and thermal properties of silica sands for laboratory experiments, internal report of the Center for Experimental Study of Subsurface Environmental Processes, Colorado School of Mines, Golden, 2009). The properties of the tap water used for the experiment are reported in Table 2. There is no cross-water flow at the boundaries between the channel and the bank sand. The sand is separated from the upstream and downstream reservoirs by a permeable membrane made of plastic with a square cell size of $100 \mu \mathrm{m}$ (Figure 1). The flow of water in the sandbox is controlled by pumping (outflow) and injection (inflow) rates to produce a constant hydraulic head gradient across the tank, allowing for measurement of the steady state self-potential distribution. During steady state conditions, the difference in head between the two reservoirs is $22.3 \mathrm{~cm}$ over a distance $L=99 \mathrm{~cm}$, so the hydraulic head gradient is 0.225 . In each sand, the permeability is assumed to be isotropic and therefore the permeability is defined as a scalar denoted by $k$. Using the measured hydraulic conductivity $K=1.52 \times 10^{-2} \mathrm{~m} \mathrm{~s}^{-1}$ for the coarse sand (Table 1), it follows that the mean Darcy velocity is given by $u=3.4 \times 10^{-3} \mathrm{~m} \mathrm{~s}^{-1}$. As $u=v$ $\phi$, the mean velocity of the pore water in the coarse-sand channel is given by $v=8.3 \times 10^{-3} \mathrm{~m} \mathrm{~s}^{-1}$. Therefore, the computed residence time is approximately $\tau=L / v=119 \mathrm{~s}$ in the coarse-sand channel. A similar calculation yields $u=2.7 \times 10^{-4} \mathrm{~m} \mathrm{~s}^{-1}, v=6.6 \times 10^{-4} \mathrm{~m} \mathrm{~s}^{-1}$, and a corresponding a residence time of $25 \mathrm{~min}$ in the fine sand. We also introduced red food dye to the upstream reservoir to independently assess the residence time. The observed residence time of the dye in the permeable channel was $167 \mathrm{~s}$ versus $16 \mathrm{~min}$ in the fine sand implying a reduced mean

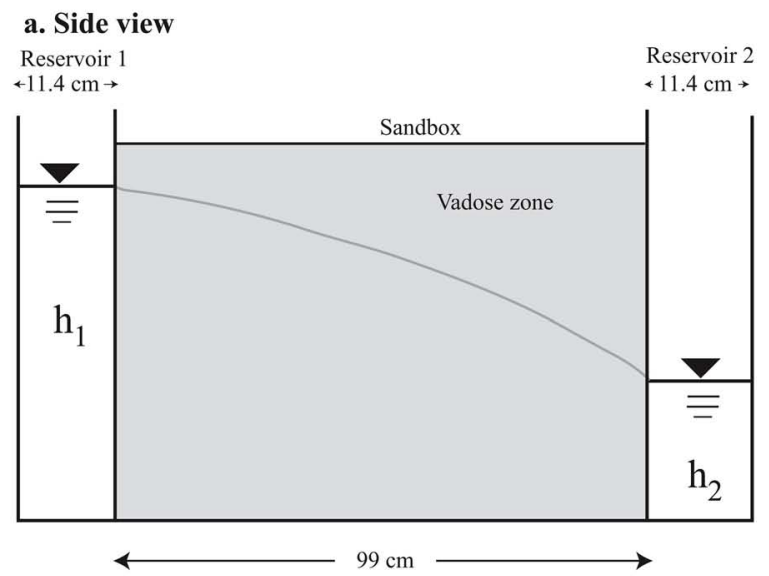

c. Picture showing the electrodes

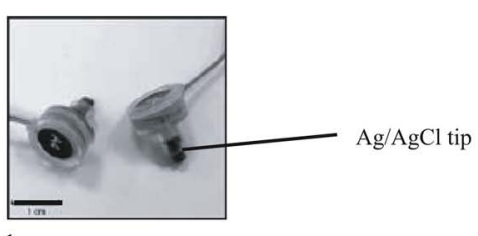

$1 \mathrm{~cm}$

b. View from above

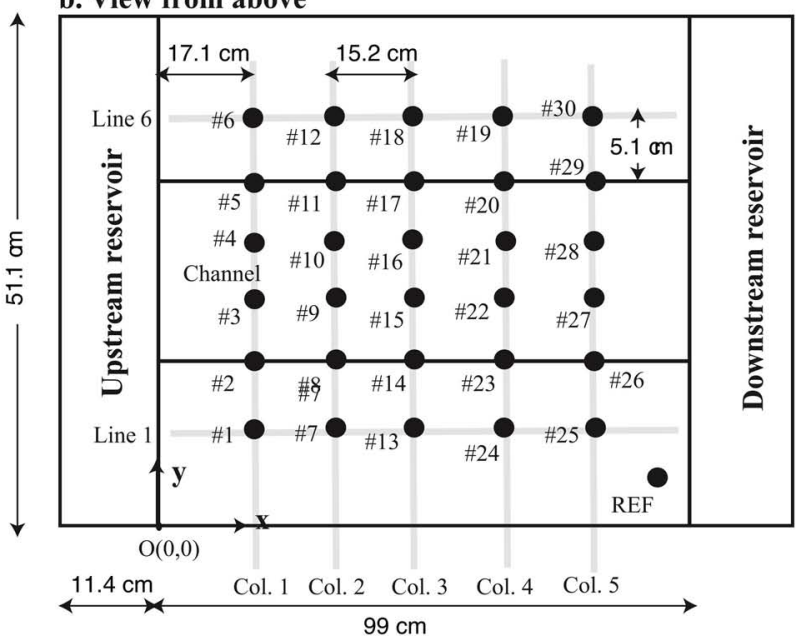

d. Picture showing the coarse sand channel

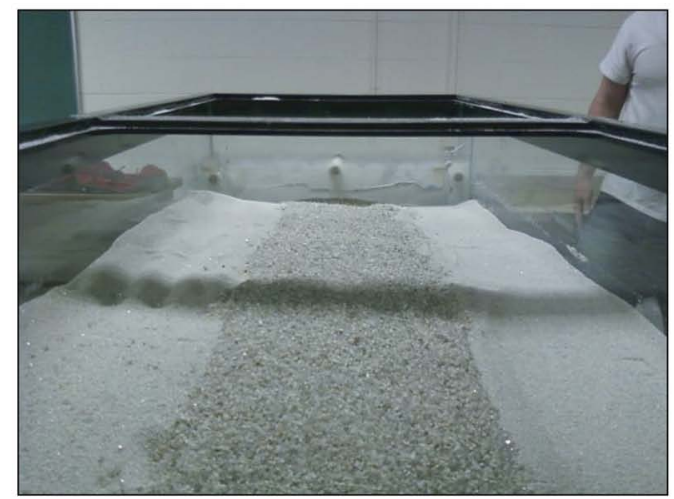

Figure 1. Sketch of the experimental setup showing the position of the channel and the positions of the nonpolarizable electrodes (small solid circles; the true size of the electrodes is much smaller than the size of the filled circles, see Figure 1b) located at the top surface of the sand. The hydraulic gradient is defined by the difference between heads $h_{1}$ and $h_{2}$ in the two reservoirs located $99 \mathrm{~cm}$ apart. The width of the tank is $51.1 \mathrm{~cm}$. REF denotes the position of the reference electrode. (a) Side view. (b) Top view (not to scale). (c) Picture showing the size of the $\mathrm{Ag} / \mathrm{AgCl}$ electrodes with the amplifiers. (d) Picture of the tank showing the coarse-sand channel between fine-grained banks. 
Table 1. Properties of the Two Sands Used in the Experiment

\begin{tabular}{lcc}
\hline \multicolumn{1}{c}{ Properties } & $\begin{array}{c}\text { Coarse Sand } \\
(\text { Channel, \#08) }\end{array}$ & $\begin{array}{c}\text { Fine Sand } \\
(\text { Banks, \#30) }\end{array}$ \\
\hline Mean grain diameter $d_{50}{ }^{\mathrm{a}}(\mathrm{m})$ & $1.51 \times 10^{-3}$ & $5.00 \times 10^{-4}$ \\
Porosity $\phi^{\mathrm{a}}$ & 0.398 & 0.410 \\
Formation factor $F$ & 3.63 & 3.48 \\
Hydraulic conductivity $K^{\mathrm{a}}\left(\mathrm{m} \mathrm{s}^{-1}\right)$ & $1.52 \times 10^{-2}$ & $1.2 \times 10^{-3}$ \\
Permeability $k\left(\mathrm{~m}^{2}\right)$ & $1.98 \times 10^{-9}$ & $2.47 \times 10^{-10}$ \\
Charge density $\bar{Q}_{V}^{\mathrm{b}}\left(\mathrm{C} \mathrm{m}^{-3}\right)$ & $8.10 \times 10^{-3}$ & $4.45 \times 10^{-2}$ \\
Conductivity $\sigma^{\mathrm{c}}\left(\mathrm{S} \mathrm{m}^{-1}\right)$ & $3.90 \times 10^{-3}$ & $4.00 \times 10^{-3}$ \\
\hline
\end{tabular}

${ }^{\mathrm{a}}$ From Sakaki and Illangasekare [2007] and T. Sakaki (internal report, Colorado School of Mines, 2009).

${ }^{\mathrm{b}}$ Using $\log _{10} \bar{Q}_{V}=-9.23-0.82 \log _{10} k$ [see Revil and Jardani, 2010].

${ }^{\mathrm{c}}$ Using $\sigma=\sigma_{f} / F$ with $\sigma_{f}=(4.9 \pm 0.2) \times 10^{-2} \mathrm{~S} \mathrm{~m}^{-1}$ at $25^{\circ} \mathrm{C}$.

velocity $v=5.9 \times 10^{-3} \mathrm{~m} \mathrm{~s}^{-1}$ in the high-permeability coarse-sand channel.

[17] The electrical potential measurements were recorded over a period of $19 \mathrm{~min}$ in a partially electrically shielded laboratory, mitigating the influence of external sources of electrical noise and eliminating the effects of radio frequency interferences. Voltages were recorded at a sample rate of $512 \mathrm{~Hz}$ with the BioSemi EEG system using 30 sintered $\mathrm{Ag} / \mathrm{AgCl}$ electrodes with integrated amplifiers. The positions of the electrodes are shown in Figure 1. They are located at the top surface of the sand and are therefore not in contact with the pore water or the salt flowing in the saturated portion of the sand. No clays were added to improve the contact resistance between the electrodes and the sand. Thus, the self-potential data are used as a nonintrusive method here in contrast to the experiments performed by Maineult et al. [2005, 2006] for which the electrodes are immersed inside the water-saturated sand. The electrodes used in this study have sintered $\mathrm{Ag}-\mathrm{AgCl}$ tips (Figure 1c), providing low noise, low offset voltages, and stable DC performances. Specifications of the BioSemi EEG system is given by Crespy et al. [2008] and Haas and Revil [2009] for laboratory applications (see also http://www.biosemi.com/). All electrical potentials are measured with respect to the reference electrode denoted REF (see Figure 1). In addition, a background self-potential distribution was recorded over a $100 \mathrm{~s}$ time window prior to salt injection. These data are used to establish a background distribution (which include the unknown electrode-to-electrode static potential differences), which will be removed in the time-lapse mapping of the anomaly associated with the transport of the salt tracer. Therefore, all self-potential anomalies during salt transport are measured with respect to the mean values and trends of the background self-potential distribution. The experiment was repeated three times and the self-potential distribution

Table 2. Composition of the Tap Water With the Assumption That Hardness is due to Calcium ${ }^{\mathrm{a}}$

\begin{tabular}{lc}
\hline Component & Concentration $\left(\mathrm{mMol} \mathrm{L}^{-1}\right)$ \\
\hline $\mathrm{Ca}^{2+}$ & 0.95 \\
$\mathrm{~K}^{+}$ & 0.09 \\
$\mathrm{Na}^{+}$ & 1.44 \\
$\mathrm{Cl}^{-}$ & 1.30 \\
$\mathrm{SO}_{4}^{2-}$ & 0.82 \\
$\mathrm{HCO}_{3}^{-}$ & 0.75 \\
\hline
\end{tabular}

${ }^{\mathrm{a}}$ This yields a Total Dissolved Solids (TDS) of $245 \mathrm{ppm}\left(\sim 5 \times 10^{-2} \mathrm{~S} \mathrm{~m}^{-1}\right.$ at $25^{\circ} \mathrm{C}$ ). Measurements were made in April-May 2009. The $\mathrm{pH}$ is 8.4. were found to be reproducible inside $1 \mathrm{mV}$. We injected the salt $(\mathrm{NaCl})$ instantaneously in the upstream reservoir (16.5 $\mathrm{g} \mathrm{NaCl}$ mixed with a very small amount of water). The volume of the upstream reservoir was $20.8 \mathrm{~L}$ (Figure 1).

[18] The self-potential snapshots shown in Figure $2 \mathrm{a}$ were obtained according to the following steps.

[19] 1. The raw BioSemi data collected in 30 channels at $512 \mathrm{~Hz}$ were loaded.

[20] 2. Next, the data were converted from units of microvolts to volts.

[21] 3. We removed the gain factor of 31.25 from the data.

[22] 4. We decimated the data by a factor of 20. First, an eighth-order Chebyshev type 1 low-pass filter was applied to the data with a cutoff frequency of $0.8\left(f_{\mathrm{s}} / 2\right) / 20=10.24 \mathrm{~Hz}$, where $f_{\mathrm{s}}$ is the original sampling frequency of the signals $(512 \mathrm{~Hz})$. The input data were filtered in forward and reverse directions to eliminate all phase distortions. Second, the smoothed signal was resampled at a lower rate equal to $f_{\mathrm{s}} / 20=512 \mathrm{~Hz} / 20=25.6 \mathrm{~Hz}$.

[23] 5. A linear function is fitted to the first $120 \mathrm{~s}$ of data in each channel (prior the salt injection) and removed from the entire data string for each channel to remove the background distribution and trends. This linear trend is usually associated with a slow drift of some of the electrodes because of their aging.

[24] 6. Time-lapse surface self-potential maps are created for data collected after salt injection at $t=120 \mathrm{~s}$ (note in Figure 2, $t=0 \mathrm{~s}$ corresponds to the time of salt injection).

[25] 7. We contoured the data in Surfer to create surface maps with an isotropic kriging approach based on a uniform variogram. These maps are shown in Figure $2 \mathrm{a}$, and Figure $2 \mathrm{~b}$ shows the time-lapse change in the electrical potential at one electrode above the coarse-sand channel.

\subsection{Results}

[26] Figure 2 shows the small self-potential fluctuations associated with the injection of the salt in the upstream reservoir. The displacement of the self-potential anomaly agrees fairly well with the velocity of the flow of the dye through the channel between the upstream and the downstream reservoir $\left(0.0059 \mathrm{~m} \mathrm{~s}^{-1}\right)$.

[27] We first need to prove that the traveling selfpotential anomaly is indeed caused by the passage of the saline plume. If we first neglect the concentration gradient in equation (11) (this assumption will be discussed further in section 5), the total current density is given by

$$
\mathbf{j}=-\frac{\sigma_{f}}{F} \nabla \psi-\bar{Q}_{V} K \nabla h
$$

where $h$ the hydraulic head (in $\mathrm{m}$ ). Therefore, the so-called streaming potential coupling coefficient (which represents a change in electrical potential with respect to a change in the hydraulic head) is defined as

$$
C=\left.\frac{\Delta \psi}{\Delta h}\right|_{j=0}=-\frac{\bar{Q}_{V} K F}{\sigma_{f}} .
$$

This sensitivity coefficient is inversely proportional to the electrical conductivity of the pore water and, as explained above, $\bar{Q}_{V}$ increases linearly with the logarithm of the 
a. Measured self-potential snapshots with respect to the background self-potential map
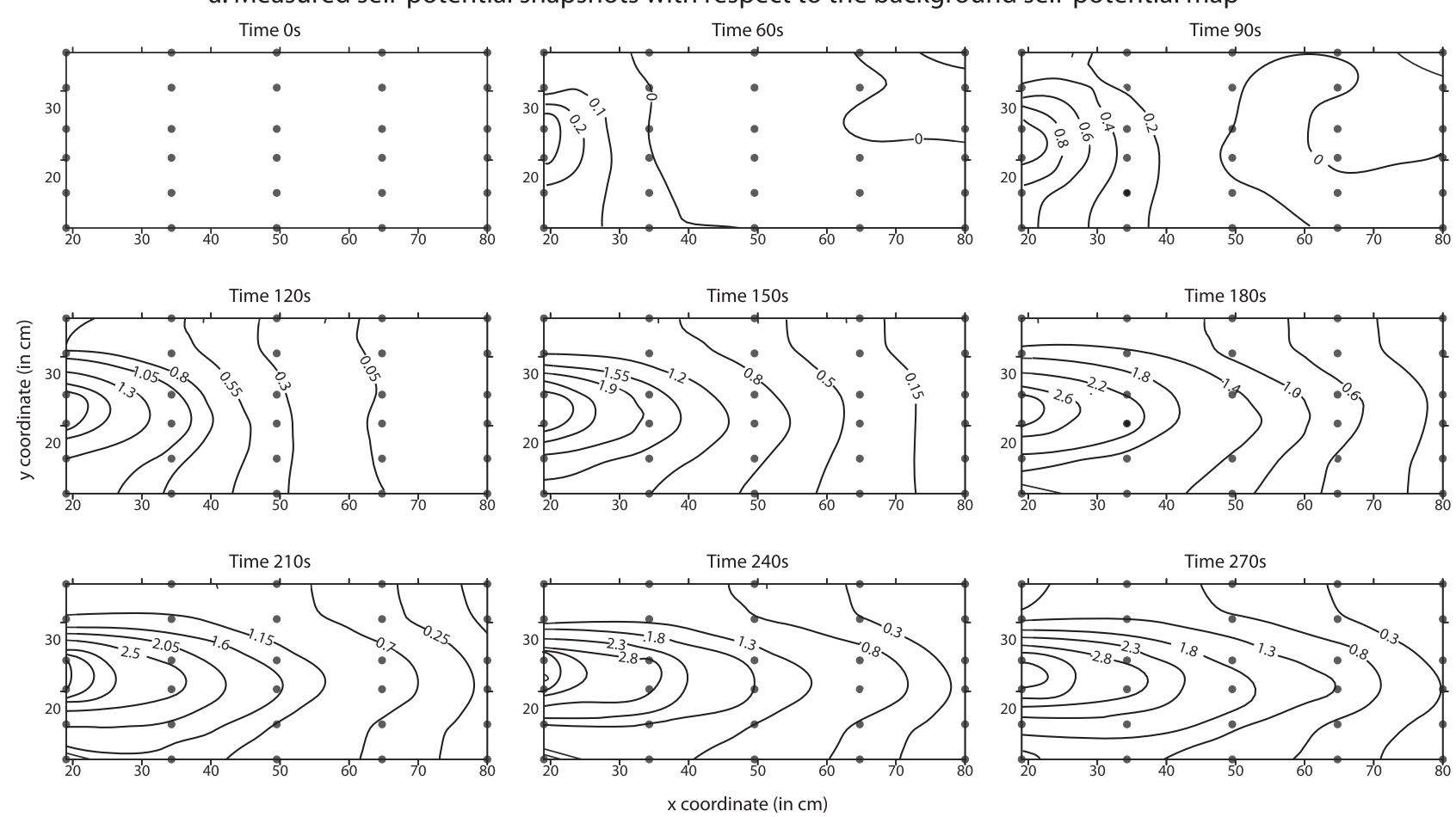

b. Time-lapse self-potential at Electrode \#3

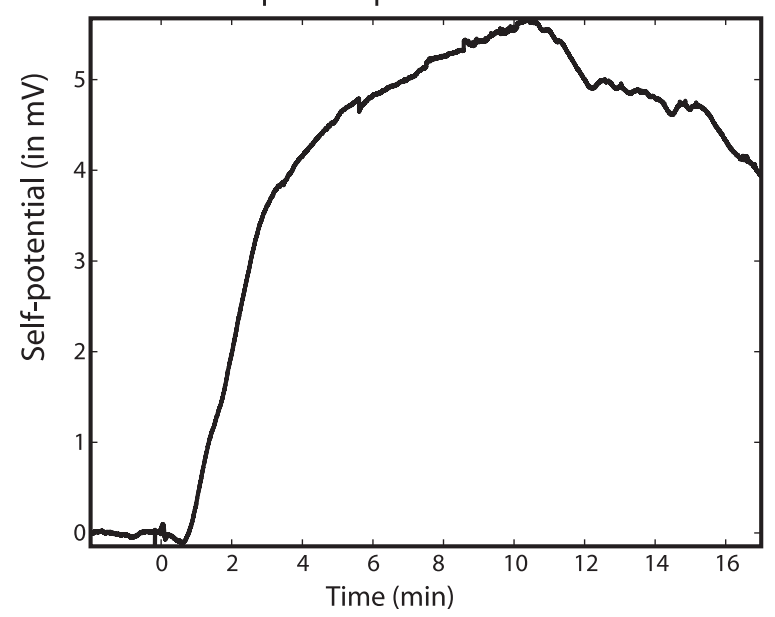

Figure 2. Observed self-potential anomalies. (a) Kriged measured self-potential anomaly contours (expressed in $\mathrm{mV})$ at different elapsed times $(t=0$ corresponds to the infiltration of the salt in the upstream reservoir). The background potential measured prior to salt injection has been removed. This explains why at $t=0 \mathrm{~s}$, there is no self-potential anomaly. Constant flow conditions are maintained for the duration of the experiment. (b) Self-potential $(\mathrm{mV})$ versus time at electrode 3.

salinity but this dependence is neglected. An order of magnitude of the expected self-potential anomaly can be obtained by measuring the streaming potential coupling coefficient and using the difference of hydraulic head between the two reservoirs. Using equation (14) and the parameters reported in Table 1, we obtain a value of the streaming potential coupling coefficient of $-9.5 \mathrm{mV} \mathrm{m}^{-1}$. The estimate is consistent with the results (streaming potential coupling coefficient versus salinity) reported by Revil et al. [2003, Figure 3] for a variety of porous materials. We have also measured directly the streaming potential coupling coefficient using the approach described by Bolève et al. [2007] using an $\mathrm{NaCl}$ solution at $0.05 \mathrm{~S} \mathrm{~m}^{-1}$ $\left(25^{\circ} \mathrm{C}\right)$. The result is $-12 \pm 2 \mathrm{mV} \mathrm{m}^{-1}$, again a value consistent with the previous estimate.

[28] Using a difference of head between the two reservoirs of $22.3 \mathrm{~cm}$, a first-order magnitude of the potential distribution is given by the product of the streaming potential coupling coefficient and the head difference. This yields a value of $2.1 \mathrm{mV}$. We cannot however use our preinjection test potential distribution because these data are very spatially noisy. The reason is that the difference of 
potential between electrodes is unknown as mentioned above. That said, as these difference of electrical potentials are constant (or linearly dependent) during the course of the experiment, it is easy to remove them as explained below in order to enhance the change in the electrical potential distribution associated with the migration of the salt.

[29] From equation (14), an increase in salinity implies a decrease of the magnitude of the (negative) streaming potential coupling coefficient (as it is getting less negative). Therefore, this change implies that during the passage of the salt plume, the intensity of the self-potential signals decreases. Because each channel is referenced with respect to its potential prior to the introduction of the salt in Figure 2, we expect the traveling self-potential anomaly observed above the channel to be positive as observed. As we introduce the saline water, the amplitude of the selfpotential anomaly decreases. Because we subtract the zeroreferenced preinjection anomaly (which was negative), we obtain a positive anomaly. In other words, it is like we are progressively 'erasing' the preinjection anomaly along the channel as the salt tracer progresses through the tank.

[30] The observed change in self-potential distribution associated with the advection/dispersion of the salt is on the order of $4 \mathrm{mV}$ (Figure 2), which is higher than the magnitude of the anomaly given above $(2.1 \mathrm{mV})$. The $2.1 \mathrm{mV}$ is the maximum possible change based on the streaming potential component. Note that in addition to this component, there is also the contribution from the diffusion potential associated with the salinity gradient and we will show below that this second contribution generates also a positive self-potential anomaly at the top surface of the tank of the same magnitude as the electrokinetic component [see Revil and Jardani, 2010].

\section{Numerical Modeling}

[31] In order to provide more insight into the origin of the measured self-potential signals, we performed a numerical simulation of the sandbox experiment. We use the finite element package Comsol Multiphysics 4.2 to solve the PDEs resulting from the combination of equations (1)-(7) above. The hydraulic problem is solved using the Richards equation as explained below. The reason is that we need to estimate the water content distribution in the vadose zone in order to obtain a realistic electrical resistivity distribution in the unsaturated sand. Therefore, we need to account for the effect of the capillary fringe, which cannot be neglected at the scale of the sandbox experiment.

[32] For unsaturated conditions, we solve the Richards equation with the van Genuchten-Mualem model [van Genuchten, 1980; Mualem, 1986] for the capillary pressure and the relative permeability of the water phase. This approach offers a simple first-order model to describe unsaturated flow. The governing equation for the flow of the water phase is [Richards, 1931]

$$
\left[C_{e}+S_{e} S\right] \frac{\partial H}{\partial t}+\nabla \cdot[-K \nabla(H+z)]=0,
$$

where $z$ is the elevation above a datum, $H$ is the total head (in $\mathrm{m}$ ), $C_{e}$ denotes the specific moisture capacity (in $\mathrm{m}^{-1}$ ) defined by $C_{e}=\partial \theta / \partial H$ where $\theta$ is the water content (dimensionless), $S_{e}$ is the effective saturation, that is related to the relative saturation of the water phase by $S_{e}=$ $\left(S_{w}-S_{w}^{r}\right) /\left(1-S_{w}^{r}\right)\left(\theta=S_{W} \phi\right.$ where $\phi$ represents the total connected porosity of the material), $S$ is the storage coefficient $\left(\mathrm{m}^{-1}\right)$, and $t$ is time. The hydraulic conductivity is related to the relative permeability $k_{r}$ and $K_{s}$, the hydraulic conductivity at saturation, by $K=k_{r} K_{s}$. With the van Genuchten-Mualem model, the porous material is saturated when the fluid pressure reaches the atmospheric pressure ( $H=0$ at the water table). The effective saturation, the specific moisture capacity, the relative permeability, and the water content are defined by

$$
\begin{gathered}
S_{e}=\left\{\begin{array}{l}
1 /\left[1+|\alpha H|^{n}\right]^{m}, \quad H<0 \\
1, \quad H \geq 0
\end{array}\right. \\
C_{e}=\left\{\begin{array}{l}
\frac{\alpha m}{1-m}\left(\phi-\theta_{r}\right) S_{e}^{\frac{1}{m}}\left(1-S_{e}^{\frac{1}{m}}\right)^{m}, \quad H<0 \\
0, \quad H \geq 0
\end{array}\right. \\
k_{r}=\left\{\begin{array}{l}
S_{e}^{l}\left[1-\left(1-S_{e}^{\frac{1}{m}}\right)^{m}\right]^{2}, \quad H<0 \\
1, \quad H \geq 0
\end{array}\right. \\
\theta=\left\{\begin{array}{l}
\theta_{r}+S_{e}\left(\phi-\theta_{r}\right), \quad H<0 \\
\phi, \quad H \geq 0
\end{array}\right.
\end{gathered}
$$

The variable $\theta_{r}$ represents the residual water content $\left(\theta_{r}=S_{w}^{r} \phi\right)$, and $\alpha, n, m=1-1 / n$, and $l$ are parameters that characterize the porous material [van Genuchten, 1980; Mualem, 1986].

[33] The values of the material properties used for the simulation are reported in Table 3 . In each sand compartment, the permeability is assumed to be homogeneous and isotropic, and therefore is defined with a constant $k$. This permeability is related to the mean grain diameter and the formation factor $F$ by [Revil and Cathles, 1999]

$$
k=\frac{d_{50}^{2}}{24 F^{3}},
$$

Table 3. Properties of the Two Sands Used in the Numerical Modeling ${ }^{\mathrm{a}}$

\begin{tabular}{lcc}
\hline \multicolumn{1}{c}{ Properties } & Coarse Sand & Fine Sand \\
\hline Median grain diameter $d_{50}(\mathrm{~m})$ & $1.51 \times 10^{-3}$ & $350 \times 110^{-6}$ \\
Porosity $\phi$ & 0.398 & 0.410 \\
Formation factor $F$ & 3.63 & 3.48 \\
Hydraulic conductivity $K\left(\mathrm{~m} \mathrm{~s}^{-1}\right)$ & $1.52 \times 110^{-2}$ & $1.20 \times 110^{-3}$ \\
Permeability $k\left(\mathrm{~m}^{2}\right)$ & $1.98 \times 110^{-9}$ & $2.47 \times 110^{-10}$ \\
Charge density $\bar{Q}_{V}\left(\mathrm{C} \mathrm{m}^{-3}\right)$ & $8.6 \times 110^{-3}$ & $4.8 \times 110^{-2}$ \\
Péclet number Pe & 1.8 & 1.0 \\
Salt diffusion coefficient $D\left(\mathrm{~m}^{2} \mathrm{~s}^{-1}\right)$ & $1.5 \times 110^{-9}$ & $1.5 \times 110^{-9}$ \\
Dispersivity $\alpha_{d}(\mathrm{~m})$ & $8.25 \times 10^{-4}$ & $4.5 \times 10^{-4}$ \\
Irreducible water content $\theta r$ & 0.023 & 0.032 \\
van Genuchten parameter $\alpha\left(\mathrm{m}^{-1}\right)$ & 12.5 & 5.0 \\
van Genuchten exponent $n$ & 9.03 & 6.57 \\
van Genuchten exponent $L$ & 1.0 & 1.0 \\
\hline
\end{tabular}

${ }^{\mathrm{a}}$ The dispersivities are modeled with $\alpha_{L}=\alpha_{T}=\alpha_{d}$. 
where $d_{50}$ is the median of the grain size distribution and the hydraulic conductivity at saturation is given by $K_{S}=k \rho_{f} g / \eta_{f}$. Note that equation (20) has been generalized recently by Revil and Florsch [2010] for an arbitrary grain size distribution. The electrical conductivity is determined using the Archie's second law inside the electrical conductivity equation:

$$
\sigma=\frac{1}{F} S_{w}^{2} \sigma_{f}
$$

Note that if $S_{w}$ goes to zero on the top part of the tank, the resistivity would tend toward infinity. To avoid such a problem in the numerical computations, we keep the water content to the irreducible water content in equation (21) (see Table 3). We obtained a irreducible water saturation of $5.8 \%$ for the coarse sand and $7.8 \%$ for the fine sand (T. Sakaki, internal report, Colorado School of Mines, 2009). In turn, this yields a resistivity of $22 \mathrm{k} \Omega \mathrm{m}$ in the coarse sand and $11 \mathrm{k} \Omega \mathrm{m}$ in the fine sand above the capillary fringe. Note that the capillary fringe is much thicker above the fine sand than above the coarse sand because of the difference in the size of the pores). That said, we use a sprinkler to slightly moisten the upper part of the tank prior starting the measurements to be sure that the contact resistance between the electrodes and the ground would be much lower than the input impedance of the voltmeter, so the true resistivity of the upper part of the tank is not well constrained. That said, we do not expect any self-potential contribution due to the moistening of the sand because the excess of electrical charge per unit volume scales with the permeability even at partial saturations [Jougnot et al., 2012]. Therefore, such a contribution is assumed to be negligible.

[34] All calculations were performed in 3-D for the flow and in $3-\mathrm{D}+$ time when solving the advection-dispersion equation and the resulting self-potential distribution. The Richards equation is solved for stationary flow conditions and, therefore, it simplifies to a Laplace-type partial differential equation:

$$
\nabla \cdot[K \nabla(H+z)]=0 .
$$

Regarding the way the model addresses salt injection, we assume complete and instantaneous mixing in the upper reservoir and use a boundary condition corresponding to an exponentially decaying salinity on the boundary of the upstream reservoir. Although it is only an approximation of the true change in the upstream salinity, it represents the time-variant nature of the dilution of the injection water throughout the experiment. The salt plume moves through the sandbox according to the advection-dispersion equation. We use insulating boundary conditions at the different boundaries where this condition applies (sides, top, and bottom boundaries, and end sides of the two reservoirs) as well as impervious boundary conditions at these boundaries except where the flux of water is injected and retrieved.

[35] The numerical simulation of the self-potential distribution prior to salt injection is shown in Figure 3. This distribution corresponds to the computed streaming potential distribution associated with the flow of the pore water. We see that the equipotentials are normal to the water table. As with the real data, we remove this contribution to focus on

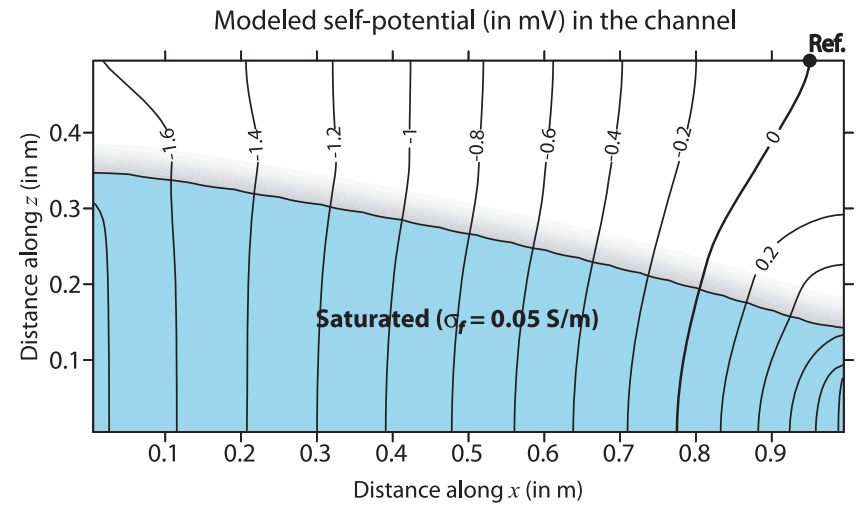

Figure 3. Numerical modeling with Comsol Multiphysics of the electrical equipotentials (expressed in $\mathrm{mV}$ ) associated with the flow of the water in the tank just prior to injection of the salt. The electrical equipotentials are perpendicular to the water table (materialized by the plain line), and the electrical field is higher downstream because of the increase of the velocity downstream. Note the equipotentials are also normal to the upper and lower boundaries because of the insulating boundary conditions.

the change in self-potential signals over time (what we call the time-lapse self-potential anomaly below).

[36] After the salt injection, the time-lapse distribution of the self-potential anomaly at the top surface of the tank is shown in Figure 4a. Analogous to the processing flow established for the sandbox experiment in section 3, the background self-potential signals (i.e., the steady state electrical response measured prior to the salt injection, see Figure 3) are removed. The self-potential signals are mainly confined to the high-permeability coarse-sand channel because of the strong resistivity contrast in the vadose zone between the preferential flow channel and the flanking lowpermeability domains. This phenomenon is also evident in the sandbox experiment, but the equipotentials are less confined to the permeable channel indicating that the resistivity distribution in the sandbox experiment may be different in the numerical simulation and the sandbox experiment for the reasons mentioned above. In Figure $4 b$, we plot the measured self-potential data (for all the snapshots shown in Figure 2) versus the modeled self-potential data shown in Figure 4a. The numerical model captures well the selfpotential fluctuations above the coarse-sand channel. The computed self-potential anomaly matches very nicely the experimental data shown in Figure 2 both in polarity and amplitude. The discrepancy observed on the banks regarding the shape of the equipotentials may be due to an incorrect assessment of the true resistivity in the vadose zone.

[37] In Figure 4c, we show a cross section of the electrical potential distribution in the middle of the channel in the flow direction. In Figure 5, we show in three dimensions how the self-potential anomaly lags behind the in situ saline pulse traveling in the permeable channel. The electrical distribution shown in Figure 4a is rather complex.

[38] If we disregard the diffusion potential contribution, the current density associated with the flow is salinity independent. This means that the distortion of the field lines is coming from the change in resistivity in the aquifer. That said, the second contribution to the current density 
a. Computed self-potential anomaly (in $\mathrm{mV}$ ) with respect to the background self-potential map

$0 \mathrm{~s}$

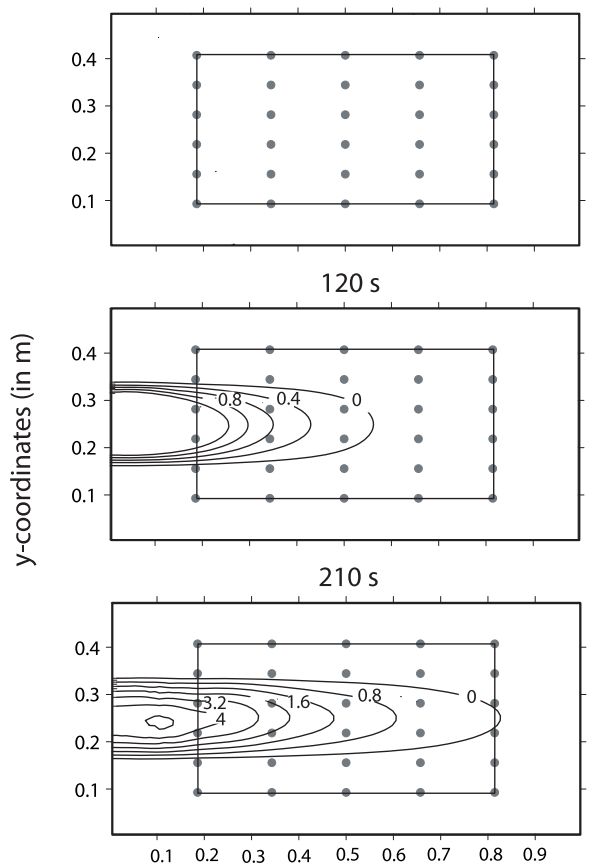

$60 \mathrm{~s}$

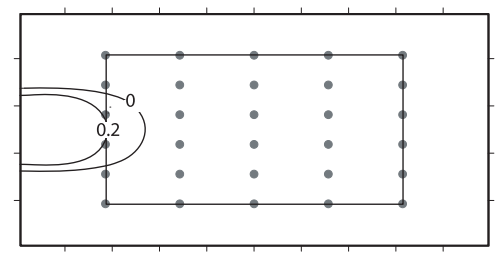

$150 \mathrm{~s}$

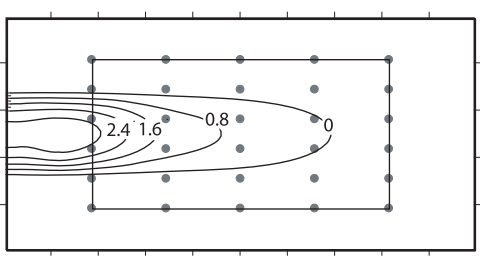

$240 s$

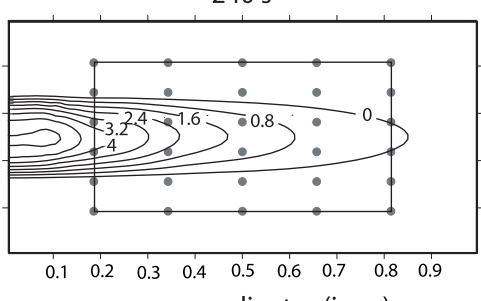

$90 \mathrm{~s}$

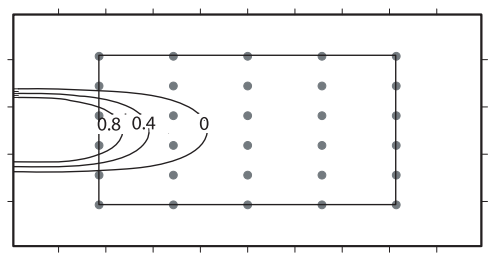

$180 \mathrm{~s}$

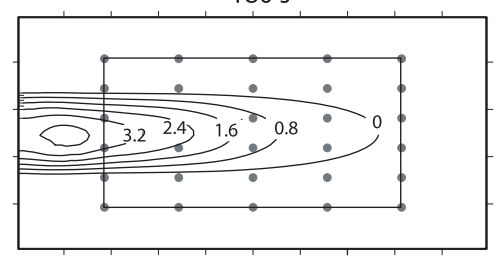

$270 \mathrm{~s}$

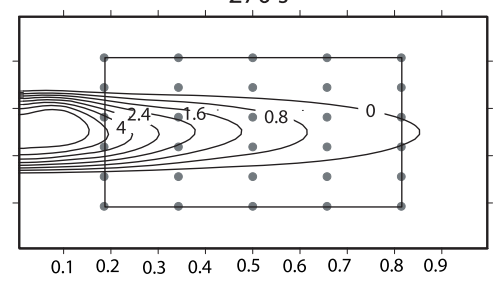

b. Modeled versus measured self-potential

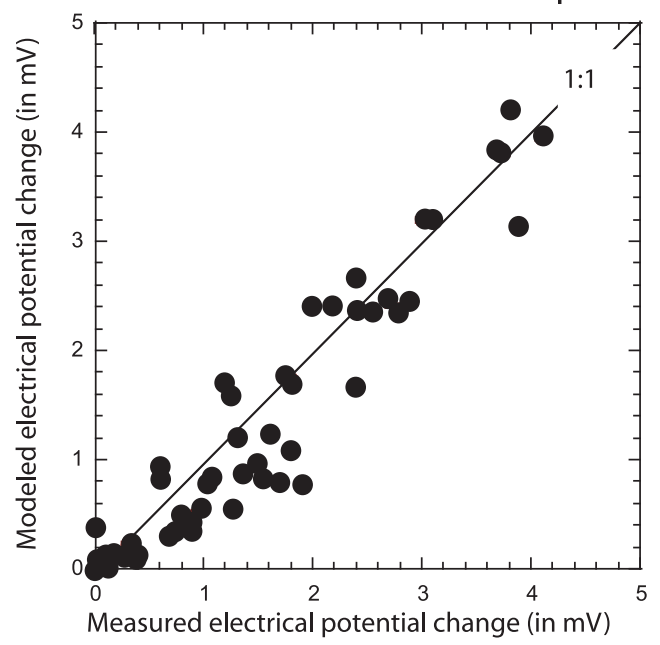

\section{c. Vertical distribution of the self-potential anomaly Electrode array (in $\mathrm{mV}$ )}

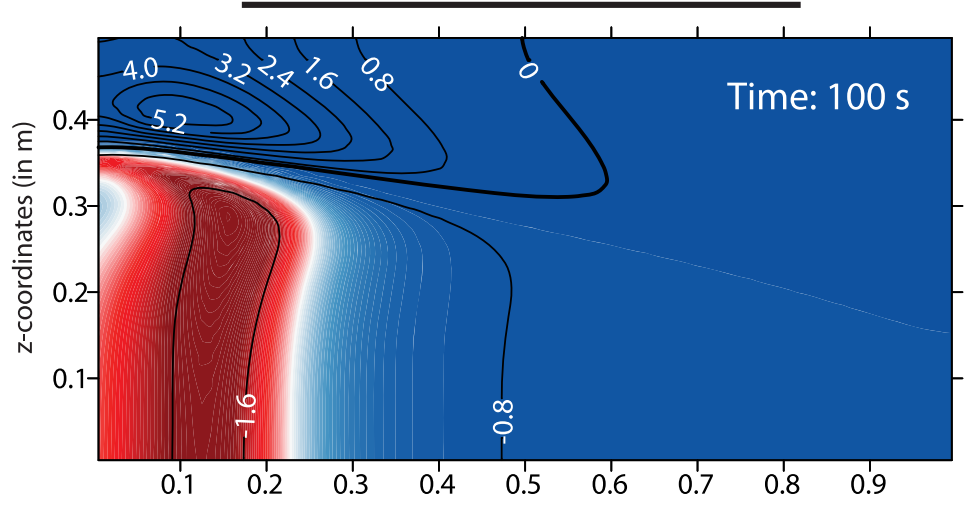

Figure 4. Computed self-potential anomaly contours at different elapsed times $(t=0$ corresponds to the injection of the salt in the upstream reservoir). (a) Result of the model. The outer rectangle corresponds to the dimension of the tank, while the inner rectangle corresponds to the area covered by the electrodes in Figure 2. Constant flow conditions are maintained during the numerical experiment, and insulating boundary conditions are applied at the top, sides, and bottom of the tank. (b) Comparison between the prediction of the model and the measured data for the two lines of electrodes just above the channel $(R=0.95)$. (c) Vertical distribution of self-potential. The colors corresponds to the conductivity (see Figure 5).

produced a positive self-potential distribution that adds to the streaming potential contribution.

[39] We investigate now the importance of the diffusion potential contribution that was neglected by Bolève et al. [2011]. As the self-potential anomaly is positive and higher than the preinjection test electrokinetic anomaly (see Figure 3 ), there is clearly more than a simple erasure of the electrokinetic anomaly by the advection-dispersion of the salt in the tank. These results imply that there is another contribution that generates a positive self-potential at the top surface of the tank [Martínez-Pagán et al., 2010; Revil and Jardani, 2010]. This additional anomaly is due to the diffusion potential associated with the salt salinity gradient.

[40] One limitation of the sandbox experiment is that we have to put a reference electrode somewhere in the sandbox where it is susceptible to spurious effects. Indeed, the 


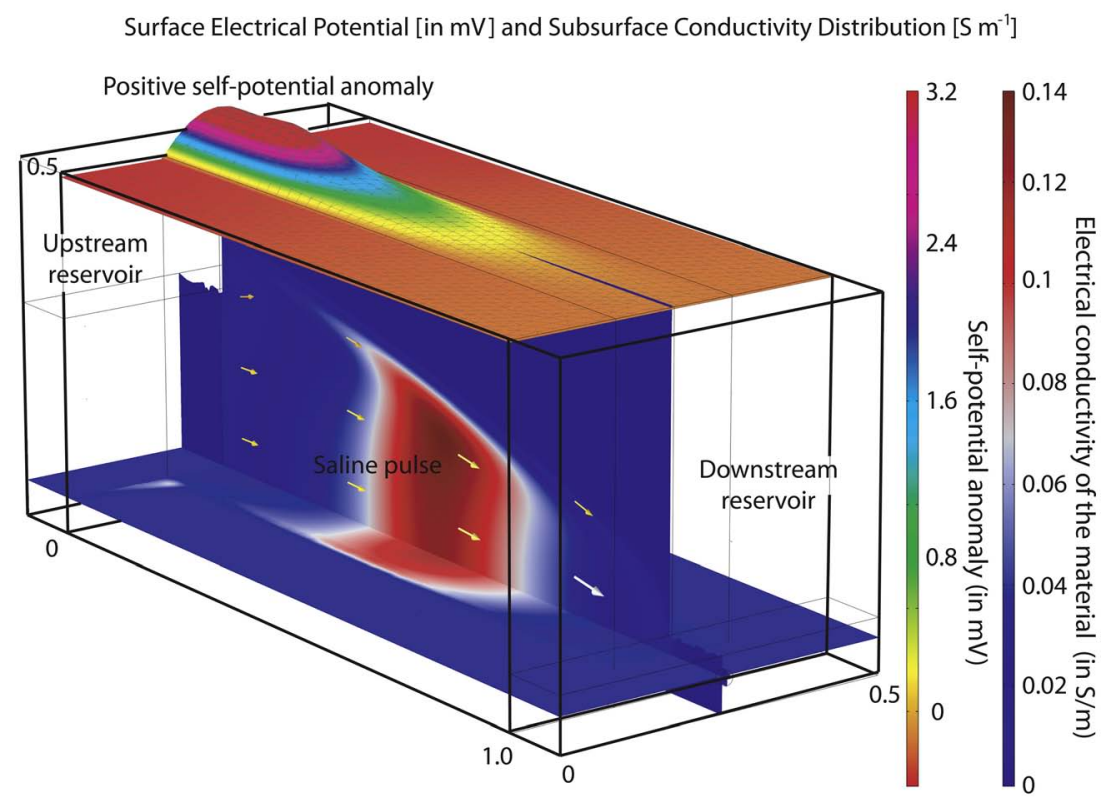

Figure 5. Snapshot (120 s after the salt injection; see Figure 4) of the 3-D distribution of the resistivity and map of the self-potential anomaly at the top surface of the tank during the saline pulse experiment. The arrows correspond to the direction of the Darcy velocity (their lengths are proportional to the intensity of the flow density vector $\mathbf{u}$ ).

absolute potential at the reference electrode is changing over time, but we assign a zero value to this location for all sampled times. Therefore, this requires an additional processing step to correct the data (section 3). The situation is different for field conditions, because the reference electrode can be placed far enough from the investigated area to avoid such spurious effects.

[41] In addition, the proper boundary conditions to be applied in the field are different from the boundary conditions applied in the laboratory. In our laboratory experiment, the boundary condition for the electrical current density at the side walls of the tank does not influence the electrical potential distribution because the changes in electrical field is mainly constrained by the position of the permeable channel. This surprising result is actually explained by the high resistance existing above the channel by comparison with the resistance of the vadose zone above the fine sand.

[42] We discuss in section 5 a case study (section 5.1) used to build a 2-D numerical analog to investigate the response in the field and how this response can be inverted to infer the permeability in a preferential fluid flow channel in an embankment (section 5.2).

\section{Application to Earth Dams and Embankments}

[43] We first discuss in section 5.1. a recent case study [see Bolève et al., 2011] showing self-potential changes associated with the injection of a salt tracer. In section 5.2., this case study is used to create a 2-D synthetic mode used to test an inversion algorithm based on a stochastic approach to invert the permeability of the flow pathway.

\subsection{Example of a Case Study}

[44] The field test reported by Bolève et al. [2011] concerns a salt tracer injection performed between two reservoirs separated by an embankment (see Figure 6a). The embankment between the two reservoirs is leaking probably because of a high-permeability channel possibly associated with internal erosion (see Wan and Fell [2008] for a description of internal erosion processes). A resistivity profile is shown in Figure 6b.

[45] A self-potential map was performed in the upstream basins using a reference electrode on the bank of the basin, and having the scanning electrode in contact with the floor of the basin. The measurements were performed along profiles with a spacing of $2.5 \mathrm{~m}$ and using Petiau electrodes. The self-potential map reveals a negative self-potential anomaly in the upstream basin just above the area where two leakages can be observed downstream (areas A1 and A2). The static self-potential anomaly was modeled by Bolève et al. [2011] but not the salt tracer test. The selfpotential map reveals a preinjection self-potential anomaly of $-55 \mathrm{mV}$ in the leaking area.

[46] In Figure 6a, we also show the position of the salt tracer injection. The resulting self-potential monitoring (using a set of $32 \mathrm{~Pb} / \mathrm{PbCl}_{2}$ nonpolarizing Petiau electrodes) is shown in Figure $7 \mathrm{a}$. In Figure $7 \mathrm{~b}$, we show the results of the monitoring of the conductivity of the water at the leaking areas A1 and A2 downstream. The selfpotential signals are recorded with a sampling frequency of $200 \mathrm{~Hz}$. Like for the laboratory test described above, the data shown in Figure $7 \mathrm{a}$ are referenced with respect the self-potential values prior the salt injection to blank the self-potential distribution existing prior the salt tracer injection.

[47] During the transport of the salt tracer, Bolève et al. [2011] observed a positive anomaly with an amplitude of $50 \mathrm{mV}$ associated with the passage of the salt tracer as discussed below. One of the reasons, as explained above, the 
a. Geometry and static self-potential map

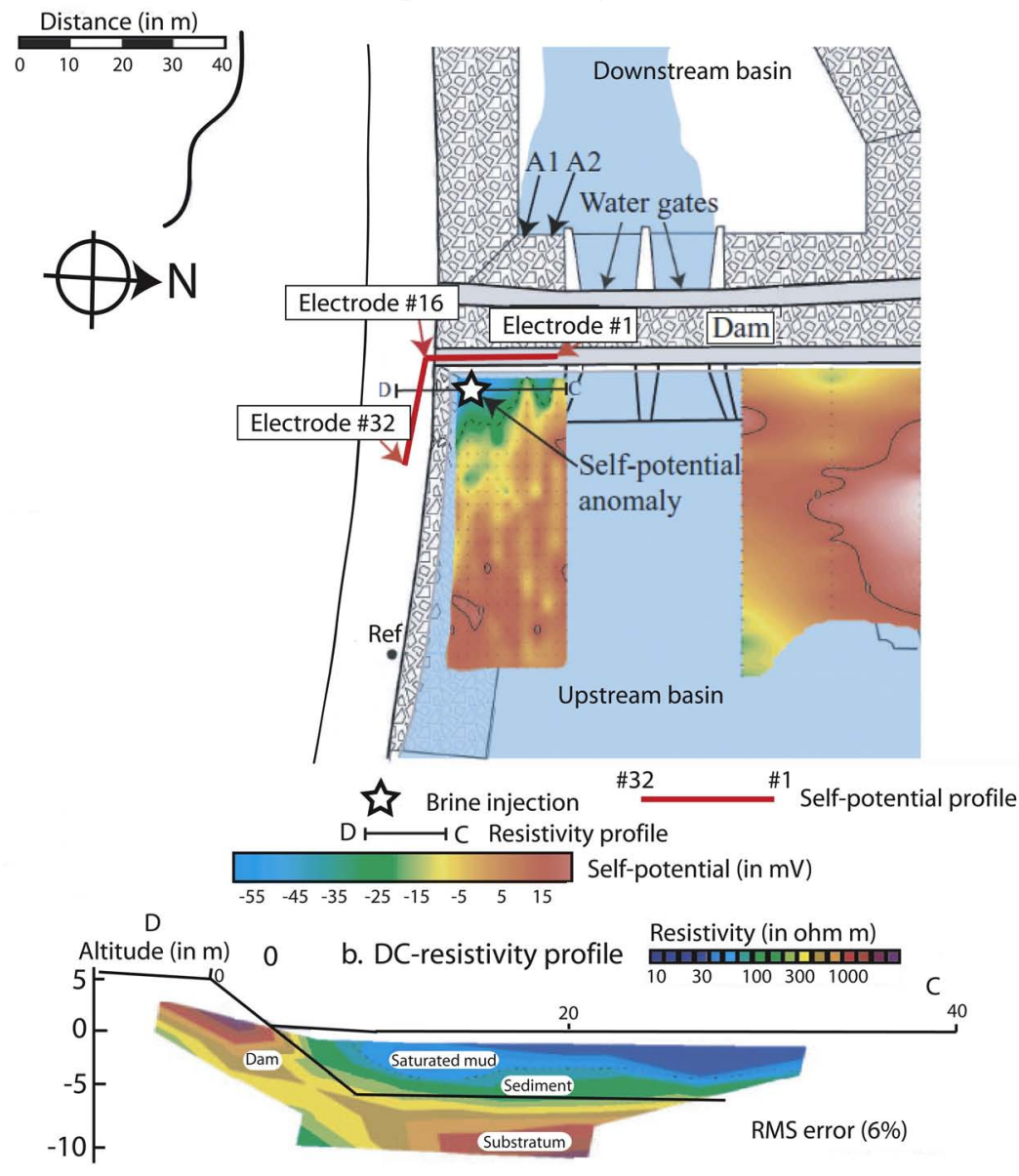

Figure 6. Sketch of the test site reported by Bolève [2009]. (a) Setting showing the position of the upstream and downstream basins, the outflow of the leaking areas (A1 and A2), the position of the monitoring self-potential profile (electrodes 1-32), the position of the brine injection (white star), and the position of the reference (Ref) for the self-potential map. Note that the preinjection self-potential anomaly is on the order of $-55 \mathrm{mV}$. (b) Direct current (DC) resistivity tomography (profile DC, data inverted with RES2DINV [Loke and Barker, 1996]).

salt tracer transport progressively erases the preinjection anomaly along the permeable pathways as the salt tracer progresses through the dam. The distance between the selfpotential profile and the two leakage areas A1 and A2 is $\sim 30 \mathrm{~m}$. This implies a pore water velocity of $4.5 \times 10^{-2}$ $\mathrm{m} \mathrm{s}^{-1}$ inside the permeable pathways The hydraulic gradient is on the order of 0.3 (see Figure 6). Using Darcy's law, this implies an apparent hydraulic conductivity of 0.15 $\mathrm{m} \mathrm{s}^{-1}$ in the permeable channel (equivalent an apparent permeability of $1.5 \times 10^{-8} \mathrm{~m}^{2}$ ). Because this apparent permeability is pretty high, it is important to check if there is an effect of the Reynolds number in this case. The Reynolds number is defined by $\operatorname{Re}=\rho_{f} u \Lambda / \eta_{f}$ where $u$ denotes the amplitude of the Darcy velocity and $\Lambda$ denotes a mean pore size called the dynamic pore radius [Johnson and Sen, 1988; Avellaneda and Torquato, 1991]. We use the following values for the parameters entering the expression of the Reynolds number: a Darcy velocity of $2.7 \times 10^{-2} \mathrm{~m} \mathrm{~s}^{-1}$ (porosity times mean velocity given above according to the Dupuit equation) and $\Lambda$ given by a $\Lambda=\sqrt{8 k F}$ [Johnson and Sen, 1988] (taking $F=2$, from Archie's law with $m=1.5$, and an apparent permeability $k_{a}=1.5 \times 10^{-8} \mathrm{~m}^{2}$, yields $\Lambda=4.9 \times 10^{-4} \mathrm{~m}$ ). This yields a Reynolds number of 13, which is not negligible as much higher than unity. According to Bolève et al. [2007], the apparent and true permeabilities are related to each other by $k_{a}=k /(1+\mathrm{Re})$. This yields a true permeability $k=2.3 \times 10^{-7} \mathrm{~m}^{2}$.

\subsection{Synthetic Test : Forward and Inverse Modeling}

[48] In order to test our approach and to see the effectiveness of inverse modeling, we develop a 2-D synthetic model inspired from the test study reported in section 5.1. Figure $8 \mathrm{a}$ shows a simple 2-D model that is a numerical analog of this case study. Our goal is to show that with this 2-D simulation, we can use the surface self-potential data (contaminated with noise) and we can invert the permeability of the preferential fluid flow pathways using a stochastic approach. The material properties for this synthetic case study are reported in Table 4 together with the dispersivities. The excess charge density $\bar{Q}_{v}$ can be obtained directly 


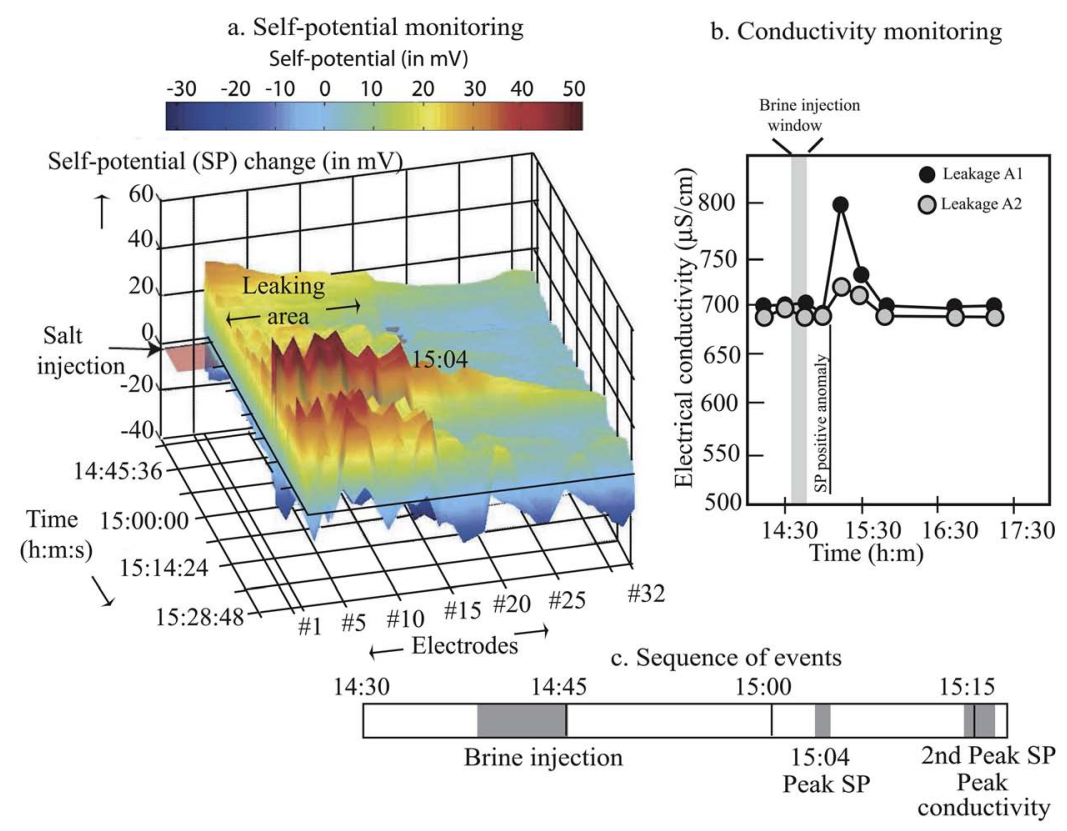

Figure 7. Results of the monitoring experiment reported by Bolève [2009]. (a) Time-lapse selfpotential signals (referenced to the preinjection values). Note that the self-potential positive anomaly is on the order of $50 \mathrm{mV}$ (followed by a negative anomaly of $-20 \mathrm{mV}$ ), which is consistent with the value of the preinjection anomaly $(-55 \mathrm{mV})$. Note the higher electrical noise level in the leaking area. (b) Monitoring of the conductivity of the water in the downstream reservoir at the position of leakages A1 and A2 (see position in Figure 6a).

from the permeability using the following relationship [see Jardani et al., 2007]:

$$
\log \left(\bar{Q}_{v}\right)=-9.2349-0.8219 \log (k)
$$

This empirical relationship has been tested for both saturated [Revil and Jardani, 2010] and unsaturated materials [see Jougnot et al., 2012], but there is most likely a small influence of salinity, $\mathrm{pH}$, and soil type in this relationship which effects are not considered in equation (23). For the conduit, this yields a charge density of $1.2 \times 10^{-3} \mathrm{C} \mathrm{m}^{-3}$ for the material in the conduit (reported in Table 4).

[49] We use Comsol Multiphysics to perform a finite element modeling of the transport of a salt tracer injecting the salt tracer directly at the entrance of the pipe as a boundary condition (see Figure 8c). The (single) recording electrode is placed in the middle of the crest of the dam. The selfpotential synthetic data are referenced to a point located upstream as shown in Figure $8 \mathrm{~b}$ (the position of this point is actually arbitrary as the potential can be shifted to zero using the potential value prior the salt injection). Insulating boundary conditions at applied at the boundaries of the domain shown in Figure 8a. The self-potential field created by the flow before the injection of the salt is shown in Figure $8 \mathrm{~b}$. The hydraulic gradient in the conduit is on the order of 0.17 and the average velocity in the conduit on the order of $0.017 \mathrm{~m} \mathrm{~s}^{-1}$. The preinjection self-potential anomaly at the inlet of the preferential flow path is approximately $-25 \mathrm{mV}$, which can be compared to the measured $-55 \mathrm{mV}$ anomaly at the inlet. Again, we are not trying to model exactly the field data.
[50] Figure 8d shows the resulting self-potential variation over time for an electrode located at the crest of the dam, while Figure $8 \mathrm{c}$ shows the salt injected over time upstream (at the entrance of the flow path). During the passage of the salt tracer below the crest of the dam, the scanning electrode (located in the middle of the crest) records a positive self-potential anomaly with an amplitude change of $15 \mathrm{mV}$ with respect to the preinjection value (Figure 8d). This positive self-potential can only be explained by having a strong diffusion current density that dominates locally the self-potential response. Indeed, as shown by MartínezPagán et al. [2010, Figure 7], the diffusion self-potential signal associated with the diffusion of a $\mathrm{NaCl}$ salt is responsible for a positive anomaly. Note that SP anomaly that would be generated by subtracting the modeled preinjection SP value from the modeled SP time series is bipolar, which is consistent with the actual field case (see Figure 7). The complex behavior shown in Figure 8d indicate that the streaming and diffusion current densities generate a complex behavior and show that depending on the conditions of the experiment, both contributions to the source current density have to be accounted for. Therefore unified models like the one produced recently by Revil et al. [2011] are very important in that respect.

[51] We now test a simple Markov chain Monte Carlo sampler, namely, the adaptive Metropolis algorithm (AMA) to invert the posterior probability distribution of the following model parameters. We assume that the shape of the self-potential anomaly measured on a set of electrodes located along the crest can be used to locate the preferential flow pathway using cross correlation (see Rozycki et al. [2006] for the development of such a method and 


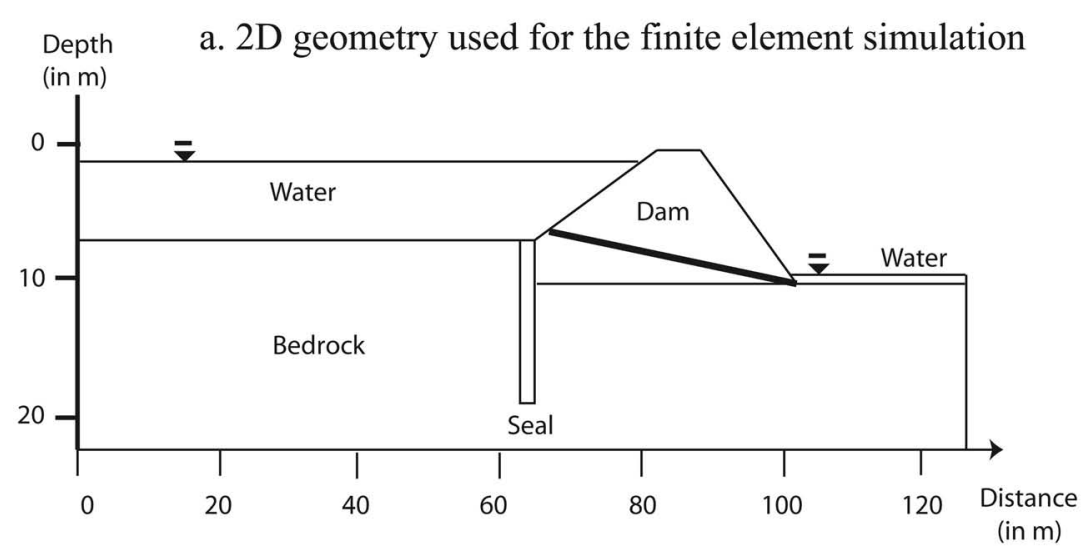

b. Self-potential (SP) distribution prior salt injection ref

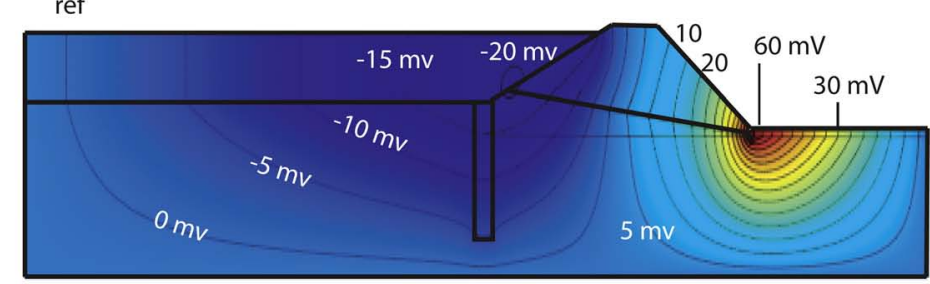

c. Injected salt concentration

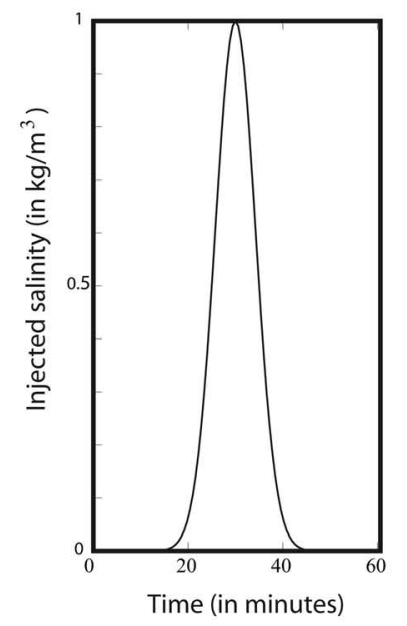

d. Measured versus inverted SP

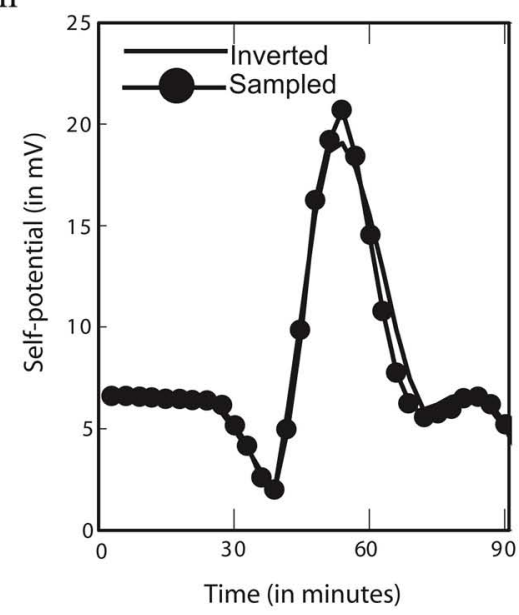

Sequence of events

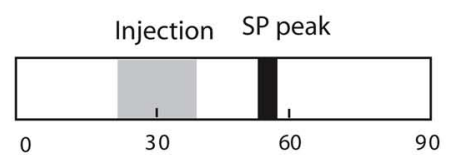

Figure 8. Numerical modeling of the synthetic case. (a) Sketch of the 2-D geometry used for the simulation (thickness in the strike direction of $1 \mathrm{~m}$ ). The material properties used in the numerical simulation are reported in Table 4 . The recording electrode is at the crest of the dam, and the reference electrode is assumed at infinity. The reference for the electrical potential is taken arbitrarily at $x=0$. (b) Simulation of the self-potential signals before salt injection. (c) Salt concentration injected upstream from the pipe. (d) Resulting self-potential changes at the crest of the dam.

case studies). We assume also that the preinjection resistivity distribution is known through resistivity tomography. AMA was introduced by Haario et al. [2001] and was recently used by Jardani et al. [2010] and Woodruff et al. [2010] for some geophysical applications.

[52] In a general case, the parameters to invert would include the geometry of the flow pathway and its material properties (porosity and permeability). That said, in the present case, the position of the pathway is pretty straightforward as the inlet is characterized upstream by self-potential mapping and the outlet is observable downstream. Therefore, we limit the model parameters to the permeability $k$ and the porosity $\phi$ of the conduit. We use $\log k$ and $\operatorname{logit}(\phi)=$ $\log (\phi /(1-\phi))$ as model parameters to impose the constraints that the permeability is positive and that the porosity is a concentration of voids between 0 and 1 . The equations used for the forward problem are the equations given in section 2: we are solving the steady state flow equation and the advection-dispersion equation for the salt tracer. We use 1000 realizations and the convergence of the chain was reached very quickly after 106 iterations (as determined from the standard deviations on the realizations of the model parameters; see Haario et al. [2001] and Woodruff et al. [2010] for further details). Once the McMC 
Table 4. Material Properties for the Synthetic Case Study ${ }^{\mathrm{a}}$

\begin{tabular}{lccc}
\hline $\begin{array}{c}\text { Material } \\
\text { Properties }\end{array}$ & $\begin{array}{c}\text { Resistivity } \\
(\Omega \mathrm{m})\end{array}$ & $\begin{array}{c}\text { Permeability } \\
\left(\mathrm{m}^{2}\right)\end{array}$ & $\begin{array}{c}\text { Excess Charge } \\
\text { Density }\left(\mathrm{C} \mathrm{m}^{-3}\right)\end{array}$ \\
\hline Water & 15 & & 0 \\
Rock & 2000 & 0 & 0 \\
Dam & 2000 & 0 & 0 \\
Leak & 150 & $2 \times 10^{-8}$ & $1.2 \times 10^{-3}$ \\
Seal & 500 & 0 & 0 \\
\hline
\end{tabular}

${ }^{\mathrm{a}}$ We use $\alpha_{L}=0.1 \mathrm{~m}$ and $\alpha_{T}=10^{-3} \mathrm{~m}$.

has converged, we use the statistics to build the posterior probability density functions on the two model parameters (Figure 9). There is a very good agreement between the peaks of the posterior probability distributions and the true value of the model parameters. The peak values of the PDF of the two model parameters are used to compute the inverted self-potential versus time curve, which compares well with the true curve in Figure 8d.

\subsection{Time-Lapse Self-Potential Versus Time-Lapse DC Resistivity}

[53] For highly permeable channels, the previous example illustrates that time-lapse self-potential is potentially more appropriate than a time-lapse DC resistivity tomography.
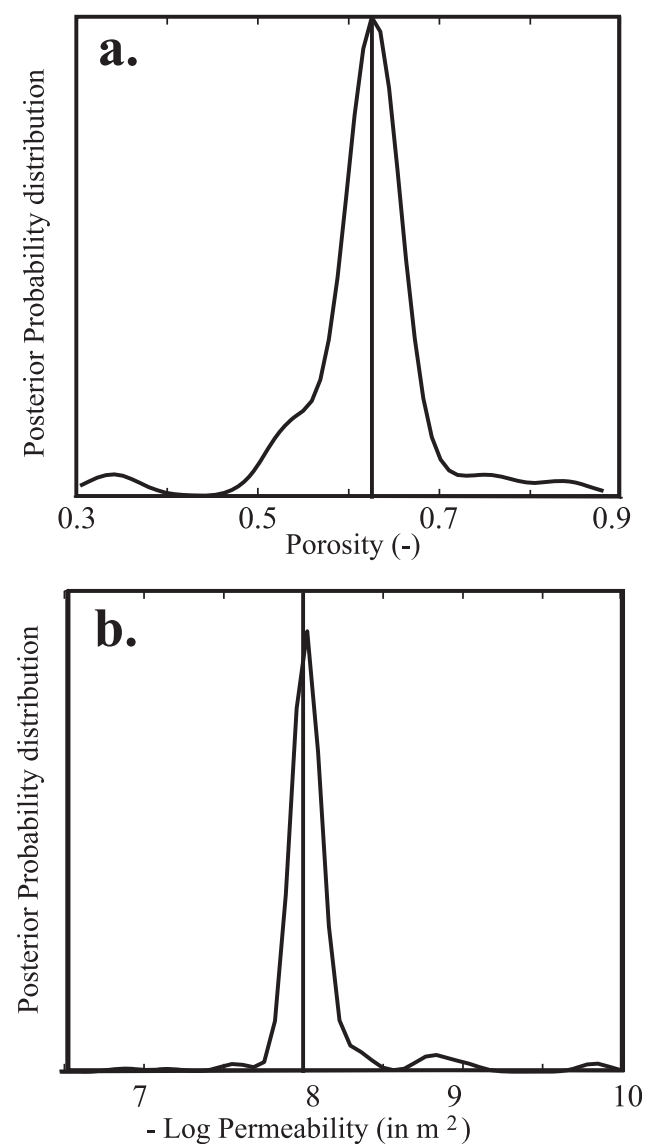

Figure 9. Posterior probability distributions of the two model parameters. (a) Porosity of the preferential fluid flow pathway. (b) Permeability of the preferential fluid flow pathway. The vertical bars correspond to the true values of the model parameters.
The reason is that DC resistivity is an active method, which takes time (often longer than the transit time of the tracer through the area of interest) to obtain 4-D snapshots of the subsurface. This is clearly the case for the previous example as the residence time of the salt over a vertical cross section was less than $20 \mathrm{~min}$. This renders time-lapse resistivity not very efficient as DC resistivity data acquisition is more time consuming than the process of advective salt transport in this case. To the contrary, the self-potential method is made in real time because it is a passive method. A background resistivity tomogram can be taken prior to the salt injection and used with the self-potential data to locate the source of the electrical disturbance during the transport of the salt tracer [see Rozycki et al., 2006].

\section{Concluding Statements}

[54] We found that a salt injection can be monitored with the self-potential method to detect preferential fluid flow pathways in a heterogeneous porous material. The injection of the salt reduces the magnitude of the (negative) streaming potential coefficient (and therefore decrease the magnitude of the self-potential field associated directly with the flow of the groundwater). In addition, the salt concentration gradient is responsible for a diffusional electrical current creating a second type of self-potential anomaly. This approach has numerous applications in hydrogeology, for instance, the detection of seepage zones in embankment dams and levees associated with internal erosion. Internal erosion corresponds to the drag of the fine-grained particles from the dam core along the seepage. This process represents a serious threat for the integrity of earth dams and embankments. The method we propose is very inexpensive as only a network of nonpolarizing electrodes connected to a sensitive voltmeter is required. The next step of this work will be to develop automatized sensor networks to perform such monitoring.

\section{Appendix A: Derivation of the Diffusional Current Density}

[55] In this appendix, we present the fundamental equations used to obtain the expressions for the diffusional current density and the diffusion coefficient of the salt in the porous material in a pore water at rest (no flow). Using the theory developed by Revil et al. [2011] (which is valid for any type of porous materials), the macroscopic constitutive equations for the coupled diffusion flux of a 1:1 salt (e.g., $\mathrm{NaCl}$ ) and current density are

$$
\left[\begin{array}{l}
2 \mathbf{j}_{d} \\
\mathbf{j}
\end{array}\right]=-\mathbf{M}\left[\begin{array}{l}
\nabla \mu_{f} \\
\nabla \psi
\end{array}\right] .
$$

The matrix of material properties $\mathbf{M}$ entering into the constitutive equation, equation (A1), is a symmetric matrix given by [Revil et al., 2011]

$$
\mathbf{M}=\left[\begin{array}{cc}
\frac{\sigma}{e^{2}} & \frac{1}{e}\left(\sigma_{(+)}-\sigma_{(-)}\right) \\
\frac{1}{e}\left(\sigma_{(+)}-\sigma_{(-)}\right) & \sigma
\end{array}\right],
$$


where $\nabla \mu_{f}=k_{b} T \nabla \ln C_{f}$ is the gradient of the chemical potential of the pore water and $\sigma=\sigma_{(+)}+\sigma_{(-)}$is the electrical conductivity of the porous material, and $\sigma_{( \pm)}$are the cationic and anionic contribution to the electrical conductivity, respectively. These equations are very general and can be applied to any type of porous materials including clean sands and shales [see, e.g., Woodruff et al., 2010]. More explicitly and using equations (A1) and (A2), the constitutive equations can be written as

$$
\begin{gathered}
\mathbf{j}_{d}=-\frac{\sigma}{2 e^{2}} \nabla \mu_{f}-\frac{1}{2 e}\left(\sigma_{(+)}-\sigma_{(-)}\right) \nabla \psi, \\
\mathbf{j}=-\sigma \nabla \psi-\frac{\sigma}{e}\left(T_{(+)}-T_{(-)}\right) \nabla \mu_{f},
\end{gathered}
$$

where $T_{( \pm)}=\sigma_{( \pm)} / \sigma$ (dimensionless) denote the macroscopic Hittorf numbers. These numbers represent the fraction of current carried by the cations or the anions through the porous material. When the total current density is zero (the diffusion current counterbalances exactly the conduction current), the so-called membrane potential is defined from equation (A4) as

$$
\left.\nabla \psi\right|_{\mathbf{j}=0}=\frac{k_{b} T}{e}\left(2 T_{(+)}-1\right) \nabla \ln C_{f} .
$$

Inserting equation (A5) into equation (A3), the diffusion flux of the salt can be written as a classical Fick's law [Revil et al., 2010] $\mathbf{j}_{d}=-D \nabla C_{f}$, where $D$ is the macroscopic (mutual) diffusion coefficient of the salt $\left(\right.$ in $\mathrm{m}^{2} \mathrm{~s}^{-1}$ ). This yields

$$
D=\frac{2 k_{b} T}{e^{2} C_{f}}\left(\frac{\sigma_{(+)} \sigma_{(-)}}{\sigma_{(+)}+\sigma_{(-)}}\right) .
$$

[56] The case where there is no contribution to electrical conductivity from the electrical double layer (which corresponds to the case analyzed in the main text) yields the following high-salinity model $\sigma=\sigma_{f} / F, \sigma_{( \pm)}=t_{( \pm)} \sigma_{f} / F$, $t_{( \pm)}=\beta_{( \pm)} /\left(\beta_{(+)}+\beta_{(-)}\right)$where $t_{( \pm)}$denote the microscopic Hittorf numbers of the cations $(+)$ and anions $(-)$ and $\beta_{( \pm)}$denote the mobilities of the cations and anions. In this case, the mutual diffusion coefficient is given by $D=D_{f} / F$. The source current density associated with the electrodiffusion of the ionic components of the salt (the diffusion current density) is given by the last term of equation (A4),

$$
\mathbf{j}_{S}=-\left(\frac{k_{b} T}{e}\right) \sigma\left(t_{(+)}-t_{(-)}\right) \nabla \ln C_{f}
$$

where we have used $\nabla \mu_{f}=k_{b} T \nabla \ln C_{f}$. Using $\nabla \ln C_{f} \approx$ $\nabla \ln \sigma_{f}$ (the pore water conductivity is proportional to the salinity) and $t_{(+)}+t_{(-)}=1$ (from their definitions), we obtain

$$
\mathbf{j}_{S}=-\left(\frac{k_{b} T}{e}\right) \sigma\left(2 t_{(+)}-1\right) \nabla \ln \sigma_{f}
$$

which is equal to the second term in the expression of the source current density used in the main text (see the second term of equation (9)). The high-salinity assumption used to obtain equation (A8) means that the Dukhin number (the ratio of surface conductivity to pore water conductivity) is small. Because the sand used in the text is pretty coarse (see Table 1) and the water pretty mineralized (see Table 2), this assumption is valid as demonstrated below. As broadly recognized in the literature, this high-salinity asymptotic limit for the Hittorf numbers is model independent [Clavier et al., 1977; McDuff and Ellis, 1979] and even occurs in an electrolyte without the need of a porous material [e.g., Newman, 1967, 1991]. In order to check the consistency of our assumption, we can compute the value of the Dukhin number for the lowest pore water conductivity used in our work, which is $5 \times 10^{-2} \mathrm{~S} \mathrm{~m}^{-1}$ at $25^{\circ} \mathrm{C}$. For a granular material like a silica sand, the electrical conductivity $\sigma$ and the Dukhin number Du are given by [Johnson and Sen, 1988; Avellaneda and Torquato, 1991; Revil and Florsch, 2010]

$$
\begin{gathered}
\sigma=\frac{1}{F}\left(\sigma_{f}+\frac{2}{\Lambda} \Sigma_{S}\right), \\
\mathrm{Du}=\frac{2}{\Lambda} \frac{\Sigma_{S}}{\sigma_{f}}
\end{gathered}
$$

where $\Sigma_{S}$ denotes the specific surface conductivity of the double layer $\left(\Sigma_{S}=2 \times 10^{-9} \mathrm{~S}\right.$ for silica [Bolève et al., 2007]), and $\Lambda$ is a dynamic pore throat radius (in $\mathrm{m}$ ) for the porous material. Revil and Cathles [1999] developed the following relationship between the formation factor $F$, the dynamic pore radius $\Lambda$, and the grain diameter $d$ for silica sands

$$
\Lambda=\frac{d}{2 m(F-1)},
$$

where $m$ denotes the cementation exponent. Therefore, we obtain

$$
\mathrm{Du}=\frac{4 m(F-1)}{d} \frac{\Sigma_{S}}{\sigma_{f}} .
$$

Taking $m=1.5, \sigma_{f}=5 \times 10^{-2} \mathrm{~S} \mathrm{~m}^{-1}$ (Table 1), $F=3.5$ (Table 2), $d=500 \mu \mathrm{m}$, we obtain $\mathrm{Du}=1.2 \times 10^{-3}<<1$. Therefore, the high-salinity asymptote used in the main text is perfectly justified.

[57] Acknowledgments. We thank NSF for funding the SmartGeo Educational Program (Project IGERT: Intelligent Geosystems; DGE0801692), the Office of Science (BER), U.S. Department of Energy (award DE-FG02-08ER646559), and Terry Young for his support at Mines. We thank the Associate Editor, F. Day-Lewis, B. Minsley, and four anonymous referees for their very useful and constructive comments.

\section{References}

Al-Saigh, N. H., Z. S. Mohammed, and M. S. Dahham (1994), Detection of water leakage from dams by self-potential method, Eng. Geol., 37(2), $115-121$.

Archie, G. E. (1942), The electrical resistivity log as an aid in determining some reservoir characteristics, Trans. Am. Inst. Min. Metall. Pet. Eng., 146, 54-62.

Asfahani, J., Y. Radwan, and I. Layyous (2010), Integrated geophysical and morphotectonic survey of the impact of Ghab extensional tectonics on the Qastoon Dam, northwestern Syria, Pure Appl. Geophys., 167, 323-338. 
Avellaneda, M., and S. Torquato (1991), Rigorous link between fluid permeability, electrical conductivity, and relaxation times for transport in porous media, Phys. Fluids A, 3, 2529-2540, doi:10.1063/1.858194.

Bolève, A. (2009), Localisation et quantification des zones de fuites dans les digues et les barrages par la méthode de potentiel spontané, $\mathrm{PhD}$ thesis, 224 pp., Univ. de Savoie, Chambery, France.

Bolève, A., A. Crespy, A. Revil, F. Janod, and J. L. Mattiuzzo (2007), Streaming potentials of granular media: Influence of the Dukhin and Reynolds numbers, J. Geophys. Res., 112, B08204, doi:10.1029/2006 JB004673.

Bolève, A., A. Revil, F. Janod, J. L. Mattiuzzo, and J.-J. Fry (2009), Preferential fluid flow pathways in embankment dams imaged by self-potential tomography, Near Surf. Geophys., 7(5), 447-462, doi:10.3997/18730604.2009012.

Bolève, A., F. Janod, A. Revil, A. Lafon, and J.-J. Fry (2011), Localization and quantification of leakages in dams using time-lapse self-potential measurements associated with salt tracer injection, J. Hydrol., 403(3-4), 242-252.

Clavier, C., G. Coates, and J. Dumanoir (1977), The theoretical and experimental bases for the "dual water" model for the interpretation of shaly sands, paper 6869 presented at 52nd Annual Fall Technical Conference and Exhibit of the Society of Petroleum Engineers of AIME, Denver, Colo., 9-12 Oct.

Crespy, A., A. Revil, N. Linde, S. Byrdina, A. Jardani, A. Bolève, and P. Henry (2008), Detection and localization of hydromechanical disturbances in a sandbox using the self-potential method, J. Geophys. Res., 113, B01205, doi:10.1029/2007JB005042.

De Witte, L. (1948), A new method of interpretation of self-potential field data, Geophysics, 13(4), 600-608.

Gex, P. (1980), Electrofiltration phenomena associated with several dam sites, Bull. Soc. Vaud Sci. Nat., 357(75), 39-50.

Haario, H., E. Saksman, and J. Tamminen (2001), An adaptive Metropolis algorithm, Bernoulli, 7, 223-242.

Haas, A., and A. Revil (2009), Electrical signature of pore scale displacements, Water Resour. Res., 45, W10202, doi:10.1029/2009WR 008160 .

Hallenburg, J. K. (1998), Standard Methods of Geophysical Formation Evaluation, 442 pp., PennWell Books, Tulsa, Okla.

Helfferich, F. (1995), Ion Exchange, Dover, New York

Jardani, A., and A. Revil (2009), Stochastic joint inversion of temperature and self-potential data, Geophys. J. Int., 179(1), 640-654, doi:10.1111/ j.1365-246X.2009.04295.x.

Jardani, A., A. Revil, A. Bolève, J. P. Dupont, W. Barrash, and B. Malama (2007), Tomography of the Darcy velocity from self-potential measurements, Geophys. Res. Lett., 34, L24403, doi:10.1029/2007 GL031907.

Jardani, A., A. Revil, E. Slob, and W. Sollner (2010), Stochastic joint inversion of 2D seismic and seismoelectric signals in linear poroelastic materials, Geophysics, 75(1), N19-N31, doi:10.1190/1.3279833.

Johnson, D. L., and P. N. Sen (1988), Dependence of the conductivity of a porous medium on electrolyte conductivity, Phys. Rev. B, 37, 3502-3510.

Jougnot, D., N. Linde, A. Revil, and C. Doussan (2012), Derivation of soilspecific streaming potential electrical parameters from hydrodynamic characteristics of partially saturated soils, Vadose Zone J., 11(1), 0086 , doi: $10.2136 /$ vzj2011.0086.

Loke, M. H., and R. D. Barker (1996), Practical techniques for 3D resistivity surveys and data inversion, Geophys. Prospect., 44, 499-523.

Maineult, A., Y. Bernabé, and P. Ackerer (2005), Detection of advected concentration and $\mathrm{pH}$ fronts from self-potential measurements, J. Geophys. Res., 110, B11205, doi:10.1029/2005JB003824.

Maineult, A., Y. Bernabé, and P. Ackerer (2006), Detection of advected, reacting redox fronts from self-potential measurements, J. Contam. Hydrol., 86, 32-52.

Malama, B., A. Revil, and K. L. Kulhman (2009a), A semi-analytical solution for transient streaming potentials associated with confined aquifer pumping tests, Geophys. J. Int., 176, 1007-1016, doi:10.1111/j.1365246X.2008.04014.x.

Malama, B., K. L. Kuhlman, and A. Revil (2009b), Theory of transient streaming potentials associated with axial-symmetric flow in unconfined aquifers, Geophys. J. Int., 179, 990-1003, doi:10.1111/j.1365-246X. 2009.04336.x.

Martínez-Pagán, P., A. Jardani, A. Revil, and A. Haas (2010), Self-potential monitoring of a salt plume, Geophysics, 75(4), WA17-WA25, doi:10. 1190/1.3475533.
McDuff, R. E., and R. A. Ellis (1979), Determining diffusion coefficients in marine sediments: A laboratory study of the validity of resistivity techniques, Am. J. Sci., 279, 666-675.

Merkler, G.-P., H. Militzer, H. Hötzl, H. Armbruster, and J. Brauns (Eds.) (1989), Detection of Subsurface Flow Phenomena, Lect. Notes Earth Sci., vol. 27, 514 pp., Springer, Berlin.

Minsley, B. J., L. B. Burton, S. Ikard, and H. M. Powers (2011), Hydrogeophysical Investigations at Hidden Dam, Raymond, California, J. Environ. Eng. Geophys., 16(4), 145-164.

Moore, J. R., A. Boleve, J. W. Sanders, and S. D. Glaser (2011), Self-potential investigation of moraine dam seepage, J. Appl. Geophys., 74, 277-286.

Mualem, Y. (1986), Hydraulic conductivity of unsaturated soils: Prediction and formulas, in Methods of Soil Analysis, part 1, Agronomy, vol. 9, edited by A. Klute, pp. 799-823, Am. Soc. of Agron., Madison, Wis.

Newman, J. (1967), Transport processes in electrolytic solutions, Adv. Electrochem. Electrochem. Eng., 5, 87-136.

Newman, J. S. (1991), Electrochemical Systems, 2nd ed., Prentice-Hall, Englewood Cliffs, N. J.

Ogilvy, A. A., M. A. Ayed, and V. A. Bogoslovsky (1969), Geophysical studies of water leakage from reservoirs, Geophys. Prospect., 22, 36-62.

Overbeek, J. T. G. (1952), Electrokinetic phenomena, in Colloid Science, Irreversible Systems, vol. 1, edited by H. R. Kruyt, 115-193, Elsevier, Amsterdam.

Panthulu, T. V., C. Krishnaiah, and J. M. Shirke (2001), Detection of seepage paths in earth dams using self-potential and electrical resistivity methods, Eng. Geol., 59, 281-295.

Pfannkuch, H. O. (1972), On the correlation of electrical conductivity properties of porous systems with viscous flow transport coefficients, in Fundamentals of Transport Phenomena in Porous Media, pp. 42-54, Elsevier, New York.

Prigogine, I. (1947), Étude thermodynamique des phénomènes irréversibles, 143 p., Dunod, Paris.

Revil, A. (1999), Ionic diffusivity, electrical conductivity, membrane and thermoelectric potentials in colloids and granular porous media: A unified model, J. Colloid Interface Sci., 212, 503-522.

Revil, A., and L. M. Cathles (1999), Permeability of shaly sands, Water Resour. Res., 35(3), 651-662.

Revil, A., and N. Florsch (2010), Determination of permeability from spectral induced polarization data in granular media, Geophys. J. Int., 181, 1480-1498, doi:10.1111/j.1365-246X.2010.04573.x.

Revil, A., and A. Jardani (2010), Stochastic inversion of permeability and dispersivities from time lapse self-potential measurements: A controlled sandbox study, Geophys. Res. Lett., 37, L11404, doi:10.1029/2010GL043257.

Revil, A., and N. Linde (2006), Chemico-electromechanical coupling in microporous media, J. Colloid Interface Sci., 302, 682-694.

Revil, A., H. Schwaeger, L. M. Cathles, and P. Manhardt (1999), Streaming potential in porous media. 2 . Theory and application to geothermal systems, J. Geophys. Res., 104(B9), 20,033-20,048.

Revil, A., V. Naudet, J. Nouzaret, and M. Pessel (2003), Principles of electrography applied to self-potential electrokinetic sources and hydrogeological applications, Water Resour. Res., 39(5), 1114, doi:10.1029/ 2001WR000916.

Revil, A., W. F. Woodruff, and N. Lu (2011), Constitutive equations for coupled flows in clay materials, Water Resour. Res., 47, W05548, doi:10.1029/2010WR010002.

Richards, L. A. (1931), Capillary conduction of liquids through porous media, Physics, 1, 318-333.

Rozycki, A. (2009), Evaluation of the streaming potential effect of piping phenomena using a finite cylinder model, Eng. Geol., 104(1-2), 98-108.

Rozycki, A., J. M. R. Fonticiella, and A. Cuadra (2006), Detection and evaluation of horizontal fractures in Earth dams using self-potential method, Eng. Geol., 82(3), 145-153.

Sakaki, T., and T. H. Illangasekare (2007), Comparison of height-averaged and point-measured capillary pressure-saturation relations for sands using a modified Tempe cell, Water Resour. Res., 43, W12502, doi:10. 1029/2006WR005814.

Sheffer, M. R. (2002), Response of the self-potential method to changing seepage conditions in enbankment dams, BSc thesis, 149 pp., Queen's University, Kingston, Ont., Canada.

Sheffer, M. R. (2007), Forward modeling and inversion of streaming potential for the interpretation of hydraulic conditions from self-potential data, PhD thesis, Univ. of B. C., Vancouver, B. C., Canada.

Sheffer, M. R., and J. A. Howie (2001), Imaging subsurface seepage conditions through the modeling of streaming potential, in Proceedings of the 
54th Canadian Geotechnical Conference, pp. 1094-1101, Can. Geotech. Soc., Richmond, B.C., Canada.

Sheffer, M. R., and J. A. Howie (2003), A numerical modelling procedure for the study of the streaming potential phenomenon in embankment dams, in Proceedings of the Symposium on the Application of Geophysics to Engineering and Environmental Problems (SAGEEP), vol. 16, pp. 475-487, Environ. and Eng. Geophys. Soc., San Antonio, Tex.

Sheffer, M. R., and D. W. Oldenburg (2007), Three-dimensional modeling of streaming potential, Geophys. J. Int., 169(3), 839-848.

Sill, W. R., and T. J. Killpack (1982), SPXCPL: Two-dimensional modelling program of self-potential effects from cross-coupled fluid and heat flow (user's guide and documentation for version 1.0), Rep. DOE/ID/ 12079-60 ESL-74, Earth Sci. Lab., Univ. of Utah, Salt Lake City.

Titov, K., V. Loukhmanov, and A. Popatov (2000), Monitoring of water seepage from a reservoir using resistivity and self polarization methods: Case history of the Petergoph fountain water supply system, First Break, $18(10), 431-435$.

van Genuchten, M. T. (1980), A closed-form equation for predicting the hydraulic conductivity of unsaturated soils, Soil Sci. Soc. Am. J., 44, 892-898.

Wan, C. F., and R. Fell (2008), Assessing the potential of internal instability and suffusion in embankment dams and their foundations, J. Geotech. Geoenviron. Eng., 134(3), 401-407.
Wilt, M. J., and D. K. Butler (1990), Geotechnical applications of the self-potential (SP) method; Report 4: Numerical modelling of SP anomalies: Documentation of program SPPC and applications, Tech. Rep. REMR-GT-6, Waterw. Exp. Stn., U.S. Army Corps of Eng., Vicksburg, Miss.

Wilt, M. J., and R. F. Corwin (1989), Numerical modeling of self-potential anomalies due to leaky dams: Model and field examples, in Detection of Subsurface Flow Phenomena, Lect. Notes Earth Sci., vol. 27, edited by G.-P. Merkler et al., pp. 73-89, Springer, Berlin.

Woodruff, W. F., A. Revil, A. Jardani, D. Numendal, and S. Cumella (2010), Stochastic inverse modeling of self-potential data in boreholes, Geophys. J. Int., 183, 748-764, doi:10.1111/j.1365-246X.2010. 04770.x.

S. J. Ikard, A. Revil, and W. F. Woodruff, Department of Geophysics, Colorado School of Mines, Green Center, 1500 Illinois St., Golden, CO 80401, USA. (sikard@mines.edu; arevil@mines.edu; wfwoodruff@ gmail.com)

A. Jardani, UMR 6143 CNRS, Université de Rouen, Bât. IRESE A, F-76821 Mont-Saint-Aignan Cedex, France.

M. Mooney and M. Parekh, Division of Engineering, Colorado School of Mines, 1500 Illinois St., Golden, CO 80401, USA. (mmooney@mines. edu; mparekh@mines.edu) 